\title{
Stability and solid-state polymerization reactivity of imidazolyl- and benzimidazolyl-substituted diacetylenes: pivotal role of lattice water $\dagger$
}

Karim Fahsi, ${ }^{a}$ Jérôme Deschamps, $\S^{\text {a }}$ Kamel Chougrani, $\mathbb{I}^{\mathrm{a}}$ Lydie Viau, ${ }^{\mathrm{a}}$ Bruno Boury, ${ }^{\mathrm{a}}$ André Vioux, ${ }^{\mathrm{a}}$ Arie van der Lee ${ }^{\mathrm{b}}$ and Sylvain G. Dutremez ${ }^{{ }^{\mathrm{a}}}$

KEYWORDS: diacetylene, imidazole, benzimidazole, hydrate, crystal structure, supramolecular interactions, topochemical polymerization, polydiacetylene, PDA

${ }^{a}$ Institut Charles Gerhardt Montpellier, UMR 5253 CNRS-UM2-ENSCM-UM1, Equipe CMOS, Université Montpellier II, Bât. 17, CC 1701, Place Eugène Bataillon, 34095 Montpellier Cedex 5, France. E-mail: dutremez@univ-montp2.fr; Fax: +33-4-67-14-38-52; Tel: +33-4-67-14-42-23

${ }^{b}$ Institut Européen des Membranes, CNRS - UMR 5635, Université Montpellier II, Case Courrier 047, Place Eugène Bataillon, 34095 Montpellier Cedex 5, France

$\dagger$ Electronic supplementary information (ESI) available: Detailed description of the C-H $\cdots \mathrm{O}$ and $\mathrm{C}-\mathrm{H} \cdots \mathrm{N}$ hydrogen bonding interactions present in 1,6-bis(1-imidazolyl)-2,4-hexadiyne monohydrate (2) and of the $\pi \cdots \pi$ and $\mathrm{C}-\mathrm{H} \cdots \pi$ interactions present in 1,6-bis(1benzimidazolyl)-2,4-hexadiyne (5) (9 pages), TGA and DSC curves of 2 up to $450{ }^{\circ} \mathrm{C}$ (Figure S3), Raman, UV-vis, and infrared spectra of 4 and poly-4 (Figures S4-S6), and observed XRPD data of 4, Rietveld fitting results, and residual profile (Figure S7). See DOI: 10.1039/c2ce26xxxx

$\S$ Present address: Université Blaise Pascal, Institut de Chimie de Clermont-Ferrand, Groupe MO, BP 10448, 63000 Clermont-Ferrand, France.

II Present address: Société Chryso, 7 rue de l'EUROPE, 45300 SERMAISES du Loiret, France. 


\section{Abstract}

1,6-Bis(1-imidazolyl)-2,4-hexadiyne (1) and 1,6-bis(1-benzimidazolyl)-2,4-hexadiyne (5) have been prepared by a novel method that consists in refluxing excess imidazole and benzimidazole with 2,4-hexadiyne-1,6-diol bis( $p$-toluenesulfonate), $p \mathrm{TS}$ (3). This procedure is a viable alternative to the widely used Hay coupling protocol in case the target diyne possesses substituents capable of deactivating the copper catalyst by complexation. Diyne $\mathbf{1}$ crystallizes as a hydrate, $\mathbf{1} \cdot \mathrm{H}_{2} \mathrm{O}(\mathbf{2})$. For this compound, water is essential to get a crystalline material, and attempts to obtain crystals without included solvent were unsuccessful. In the structure of $\mathbf{2}$, the organic fragments organize around the water molecule and interact with it through a dense network of hydrogen bonds. The $\mathrm{C} \equiv \mathrm{C}-\mathrm{C} \equiv \mathrm{C}$ moieties are not oriented suitably for topochemical polymerization, and when trying to alter the organization of the crystal by heating so as to induce polymerization, water is lost in an abrupt fashion that leads to instantaneous decomposition into polyaromatic-like species. Similar results were observed when water was removed in vacuo at room temperature. The benzimidazole-containing compound can be crystallized with water molecules (4) or without (5). X-ray crystallography shows that the structure of $\mathbf{5}$ is organized by numerous $\mathrm{C}-\mathrm{H} \cdots \mathrm{N}, \mathrm{C}-\mathrm{H} \cdots \pi$, and imidazolyl...imidazolyl $\pi-\pi$ interactions. The diacetylene molecules almost have the right arrangement for topochemical polymerization, with possibly reacting $\mathrm{C} \equiv \mathrm{C}-\mathrm{C} \equiv \mathrm{C}$ fragments not being parallel, a rare situation in diacetylene chemistry. Yet, experiments show that topochemical polymerization does not occur. Incorporation of water in the lattice of 5 leads to a solvate that is topochemically reactive. Unlike $\mathbf{2}$, however, water molecules in $\mathbf{4}$ are not isolated but are organized as ribbons. Spectroscopic characterization of the polymer of 4 indicates that it is a blue phase polymer, with water coordinated to it. This study shows that it is possible to use water, and more generally solvent molecules, to transform a nonreactive diacetylene into a reactive one, even though this approach is less predictable than the cocrystal approach developed by Fowler, Lauher, and Goroff. The solvate approach is simple to implement, quite versatile because of the large range of solvents available, and one does not face the problem of having to remove the host in case one needs to recover the polymer. Previous studies describing a similar approach are scarce. 


\section{Introduction}

Diacetylenes (DAs) are an intriguing class of molecules owing to their ability to polymerize in the solid state. ${ }^{1}$ Solid-state polymerization of DAs takes place through 1,4-addition between neighboring $\mathrm{C} \equiv \mathrm{C}-\mathrm{C} \equiv \mathrm{C}$ fragments, leading to polydiacetylenes (PDAs). ${ }^{2-4}$ PDAs are 1D structures with a $\pi$-conjugated backbone consisting of an alternation of double and triple bonds (Scheme 1). The advantages of solid-state diacetylene polymerization are at least twofold: first, it requires no catalyst and no solvent, so it may be regarded as a "green" process. Second, in favorable cases, perfectly ordered crystals of the polymer are obtainable., ${ }^{6}$ Thus, the geometry of the polymer chains in these crystals can be determined accurately by single-crystal X-ray diffraction. ${ }^{7-9}$ Also, it is possible to study the electronic properties of the chains in the absence (or near absence) of disorder. ${ }^{10}$

A set of crystal packing requirements must be fulfilled for solid-state polymerization of DAs to occur; these requirements are compiled under the name "Topochemical Principle". ${ }^{11}$ These geometrical criteria, which are necessary but not sufficient conditions for such a polymerization to take place, ${ }^{11-13}$ are depicted in Scheme 1: i) the translational period d of the monomer is in the range of 4.7 to $5.2 \AA$; ii) $R_{v}$ is smaller than $4 \AA$, with a lower limit of $3.4 \AA$, which represents the van der Waals contact distance of the two rods; iii) the angle $\gamma$ between the diacetylene rod and the translational vector is close to $45^{\circ}$. All three geometrical requirements must be met in order to secure a close contact between the $C_{1}$ atom of one diacetylene rod and the $\mathrm{C}_{4}$ atom of the neighboring rod, in the reactive monomer crystal. ${ }^{4,14}$ The upper limit for $\mathrm{R}_{1,4}$ as quoted by Baughmann is $5 \AA^{2}$, but according to Huntsman, this limit should not be much greater than $4.3 \AA .{ }^{14}$

Suitable orientation of the diacetylenic molecules in the crystal lattice is frequently achieved by intermolecular hydrogen bonding, and this situation was recognized early on by Wegner. ${ }^{1}$ Thus, DAs possessing hydroxyl, ${ }^{15,16}$ sulfonate, $^{17,} 18$ urethane, ${ }^{19-21}$ amide, ${ }^{22,}{ }^{23}$ and urea $^{24}$ groups have been prepared in the hope of organizing the $\mathrm{C} \equiv \mathrm{C}-\mathrm{C} \equiv \mathrm{C}$ moieties by hydrogen bonding. Weaker types of hydrogen bonds such as $\mathrm{CH}_{2} \cdots \mathrm{N} \equiv \mathrm{C}$ contacts ${ }^{25}$ function equally well, and also, $\mathrm{C}-\mathrm{H} \cdots \pi$ interactions can be used for such purpose. ${ }^{8,9}$

In case these interactions are ineffective at organizing suitably DA molecules in the crystal lattice, one way of solving the problem is to look for other polymorphs. ${ }^{16,26}$ This solution is simple to implement, yet it does not always work and is hardly predictable. Alternatively, it is possible to use tools from the crystal engineer arsenal, especially 
cocrystals. Two approaches dealing with cocrystals have been followed in the recent literature. In the first approach, Fowler, Lauher, and Goroff have prepared cocrystals between urea- or oxalamide-containing hosts and diacetylene-containing guests. In these assemblies, the ditopic host and ditopic guest interact with one another through hydrogen ${ }^{27-34}$ or halogen $^{33}$, 35-39 bonds, creating 1D chains. The chains are connected in a perpendicular direction by hydrogen bonding between the urea- or oxalamide-containing hosts. In the second approach, Grubbs and co-workers, ${ }^{40}$ and later on Frauenrath and colleagues, ${ }^{41,42}$ have made use of weak face-to-face $\pi \cdots \pi$ interactions. Specifically, they have shown that diacetylenes bearing perfluorophenyl substituents and DA molecules with phenyl groups could assemble into cocrystals through perfluorophenyl $\cdots$ phenyl contacts and that, in these cocrystals, the $\mathrm{C} \equiv \mathrm{C}$ $\mathrm{C} \equiv \mathrm{C}$ fragments were oriented suitably for solid-state polymerization. A third possibility exists that does not rely upon the formation of a cocrystal and that is based on coordination chemistry. $^{43}$

In principle, it would be a lot easier if one could just use solvent molecules to orient suitably diacetylenes in the crystal lattice. Such a strategy would spare one the effort of synthesizing the structure-directing component necessary for DA organization in the cocrystal approach described previously. ${ }^{37}$ There is some literature concerning the preparation and structural characterization of inclusion compounds containing diacetylenic hosts. These hosts are called "wheel-and-axle" molecules because they possess bulky end groups. The rigid $\mathrm{C}_{4}$ spacer keeps the end groups apart and prevents close packing of the host. Thus, voids are created in the structure where solvent molecules can nest. Toda and colleagues have prepared a large number of clathrates using 1,1,6,6-tetraphenyl-hexa-2,4-diyne-1,6-diol as a host. ${ }^{44-46}$ In general, in these clathrates, solvent molecules with polar groups are included as a result of their interactions with the hydroxyl groups from the diacetylenic diol, ${ }^{47,}{ }^{48}$ yet $\pi$-donors and haloalkanes can be incorporated as well. ${ }^{47}$ Following this seminal work, Hart and coworkers $^{49}$ have subjected $\mathrm{Ar}_{3} \mathrm{CC} \equiv \mathrm{C}-\mathrm{C} \equiv \mathrm{CCAr}_{3}$ diacetylenes ( $\mathrm{Ar}=$ phenyl, $p$-biphenyl, 4methoxyphenyl) to solvent complexation studies and found that these diynes produced clathrates with arenes and chloroform. More recently, Brouty et al. ${ }^{50}$ and ourselves, ${ }^{51}$ have shown that diacetylenic molecules bearing heteroelement-containing substituents $\mathrm{R}_{3} \mathrm{MC} \equiv \mathrm{C}$ $\mathrm{C} \equiv \mathrm{CMR}_{3}\left(\mathrm{M}=\mathrm{Si}, \mathrm{Sn}, \mathrm{Pb} ; \mathrm{R}_{3}=\mathrm{Aryl}_{3}, \mathrm{Aryl}_{2} \mathrm{Me}\right)$ have the same propensity for solvent inclusion as their all-carbon counterparts. In terms of DA polymerization, the most important outcome from all of these investigations is that the included solvent molecule is unable to modify the organization of the diacetylenic host so as to render topochemical polymerization 
possible, no matter what the strength of interaction between the two. There are, however, two exceptions: the first exception was reported by Ouyang et al. ${ }^{30}$ These workers showed that penta-2,4-diynyl 3,5-dihydroxybenzoate, a resorcinol-appended diacetylene, crystallizes as a monohydrate from $\mathrm{MeOH}-\mathrm{H}_{2} \mathrm{O}$. In this clathrate, water molecules position adjacent $\mathrm{C} \equiv \mathrm{C}-\mathrm{C} \equiv \mathrm{C}$ fragments in such a way that monomer crystals transform smoothly into polymer crystals upon heating to $50{ }^{\circ} \mathrm{C}$. The second exception is an old example. In 1980, Patel and colleagues published a paper in which they described the solid-state polymerization of 2,4-hexadiyne1,6-bis(m-tolylurethane), $\mathrm{HD}_{m}$ TU. ${ }^{19}$ They found that this DA is moderately reactive and that, upon irradiation with $\gamma$-rays, no more than $35 \%$ conversion to the polymer could be achieved. They also found that this DA could be converted into a more reactive form upon exposure to $p$-dioxane vapor. This new form, which incorporates 0.5 molecule of $p$-dioxane per molecule of diacetylene, polymerizes quantitatively when subjected to a $\gamma$-ray dose slightly greater than $50 \mathrm{MRad}$. Neither the X-ray crystal structure of $\mathrm{HD}_{m} \mathrm{TU} \cdot 0.5$-dioxane nor that of its polymer were reported in this work. However, the structure of poly-HDPU-0.5 p-dioxane is known (poly-HDPU $=\operatorname{poly}[2,4$-hexadiynylenebis(phenylurethane) $]$ ) that shows that the $p$-dioxane molecule is involved in two centrosymmetrically related $\mathrm{N}-\mathrm{H} \cdots \mathrm{O}$ hydrogen bonds with the polymer. $^{52}$

We wish to continue this theme here using 1,6-bis(1-imidazolyl)-2,4-hexadiyne (1) and 1,6-bis(1-benzimidazolyl)-2,4-hexadiyne (5) (see structures in Scheme 2). The solid-state polymerization of DAs with pyridine, quinoline, and pyrimidine substituents has been reported before, ${ }^{27-29}, 31-33,53-56$ but as far as we know, DAs bearing imidazole and benzimidazole groups have never been tested for topochemical polymerization. Imidazole and benzimidazole moieties are more basic than any of the previously used heterocycles, ${ }^{57}$ so we anticipate that molecular assemblies with novel architectures might be accessible, as it was observed with imidazolyl-containing haloalkenes and haloalkynes. ${ }^{58}$ Furthermore, as an extra bonus, PDAs bearing imidazole and benzimidazole groups should be amenable to derivatization, especially by protonation, quaternization, and complexation to a metal. ${ }^{53} \mathrm{We}$ report in this study that both $\mathbf{1}$ and $\mathbf{5}$ are capable of binding water molecules. Crystallographic characterization of the hydrate and anhydrate forms of these diacetylenes shows that hydrogen bonding competes with $\mathrm{C}-\mathrm{H} \cdots \pi$ and $\pi \cdots \pi$ interactions and affects the organization of the molecules. A qualitative evaluation of the strengths of interaction is done on the basis of a detailed metrical analysis, yet the purpose of this work is not to provide precise energy values. Such a valuable piece of information is difficult to obtain and requires a study of its own. We 
rather wish to show how the presence of water in the lattice of these molecules is beneficial in some respects and detrimental in others in terms of stability and polymerization reactivity. In particular, in the case of $\mathbf{1}$, the presence of water is essential to create an organized structure; single crystals of this DA cannot be obtained in the absence of water. In the structure of $\mathbf{1} \cdot \mathrm{H}_{2} \mathrm{O}(\mathbf{2})$, each water molecule interacts strongly with several neighboring DA molecules, but the $\mathrm{C} \equiv \mathrm{C}-\mathrm{C} \equiv \mathrm{C}$ fragments are not oriented suitably for topochemical polymerization. When trying to alter the organization of the crystal by heating so as to induce polymerization, water is lost in an abrupt fashion that leads to instantaneous decomposition of the diacetylene. In the case of 5, the material that is obtained after evaporation of the solvent mixture used for chromatographic purification is a monohydrate (4). Single crystals of $\mathbf{4}$ could not be obtained, so its structure had to be determined by Rietveld refinement. This form exhibits fairly good solid-state polymerization reactivity. When $\mathbf{4}$ is crystallized from dichloromethane, an anhydrate is obtained that is nonreactive. 


\section{Results and discussion}

\section{Syntheses}

1,6-Bis(1-imidazolyl)-2,4-hexadiyne (1) is a novel compound. Initial attempts to synthesize this molecule were made by use of oxidative dimerization of 1-propargylimidazole ${ }^{58}$ following the Hay coupling protocol, ${ }^{59}$ with DME (1,2-dimethoxyethane) as a solvent. A green powder insoluble in common laboratory solvents was obtained that showed an intense Raman band at $2250 \mathrm{~cm}^{-1}$, typical of diacetylenes. Elemental analysis revealed the presence of carbon, hydrogen, nitrogen, chlorine, and copper percentages consistent with the formation of a coordination compound between 1 and copper, but the exact stoichiometry of this compound could not be determined. The green powder was treated with several extractants known to complex copper, viz. ethylenediaminetetraacetic acid (EDTA), 8-hydroxyquinoline, and dithizone, but these efforts were unsuccessful. Eventually, the solid was treated with an excess of potassium cyanide ( $\sim 40$ equiv) in a two-phase $\mathrm{CH}_{2} \mathrm{Cl}_{2}-\mathrm{H}_{2} \mathrm{O}$ solvent mixture, and indeed, uncomplexed $\mathbf{1}$ was recovered in the organic layer. ${ }^{60}$ Clearly, this synthetic procedure is inappropriate for large-scale preparations of $\mathbf{1}$, so we looked for a safer route. We have found that 1 forms when 2,4-hexadiyne-1,6-diol bis( $p$-toluenesulfonate $)^{61}$ (3) is allowed to react with an excess of imidazole in refluxing dichloromethane (Scheme 2). ${ }^{62}$ Chromatographic purification of 1 with use of a $\mathrm{CH}_{2} \mathrm{Cl}_{2}-\mathrm{CH}_{3} \mathrm{OH}$ solvent mixture (94:6 v/v) followed by slow evaporation of the solvents gives $\mathbf{1} \cdot \mathrm{H}_{2} \mathrm{O}(2)$ in $55 \%$ yield.

1,6-Bis(1-benzimidazolyl)-2,4-hexadiyne (5) is a known compound that has been prepared in the past by oxidative dimerization of 1-propargylbenzimidazole under the Glaser coupling conditions. ${ }^{63}$ Various methods to prepare 1-propargylbenzimidazole can be found in the literature with yields ranging from 30 to $75 \% .^{63,64}$ We have employed the same synthetic procedure as that used to prepare $\mathbf{1}$, and after chromatographic purification, $\mathbf{5} \cdot \mathrm{H}_{2} \mathrm{O}$ (4) was obtained in $60 \%$ yield. Anhydrate 5 is obtained by crystallization of $\mathbf{4}$ from $\mathrm{CH}_{2} \mathrm{Cl}_{2}$.

\section{Structure of 1,6-bis(1-imidazolyl)-2,4-hexadiyne monohydrate (2)}

1,6-Bis(1-imidazolyl)-2,4-hexadiyne co-crystallizes with one water molecule. This situation is frequently encountered for imidazolyl-containing compounds; especially, biomolecules and drugs such as adenine, theophylline, ornidazole, and xanthosine are known to crystallize as hydrates. ${ }^{65-68}$ Hydrate 2 crystallizes in the orthorhombic space group Pbcn with $Z=4$ (Table 1). There is one-half of a diacetylene molecule in the asymmetric unit and one-half of a water 
molecule. ${ }^{69}$ Both molecules are located on a two-fold rotation axis. When viewed down the crystallographic $a$ axis (Figure 1), the presence of a single layer stacking arrangement is evident: layers made of $\mathrm{CH}_{2}-\mathrm{C} \equiv \mathrm{C}-\mathrm{C} \equiv \mathrm{C}-\mathrm{CH}_{2}$ fragments are separated by regions that contain exclusively imidazolyl groups and water molecules. In these regions, imidazolyl groups are interdigitated, but there is no significant $\pi-\pi$ interaction between them. The smallest $\mathrm{Cg} \cdots \mathrm{Cg}$ distance ( $\mathrm{Cg}$ is the centroid position of the imidazolyl ring) between two nearby imidazolyl groups is $4.986 \AA$. This distance is much larger than the 3.4-3.8 $\AA$ range typically found in systems that exhibit sizeable $\pi-\pi$ stacking interactions. ${ }^{70}$ The next smallest $\mathrm{Cg} \cdots \mathrm{Cg}$ distance between imidazolyl moieties is $5.626 \AA$.

Diacetylenic units are too far away from one another to undergo topochemical polymerization: the closest distance, $R_{1,4}$, between the $\mathrm{C}_{1}$ carbon atom of a $\mathrm{C}_{1} \equiv \mathrm{C}-\mathrm{C} \equiv \mathrm{C}_{4}$ fragment and the $\mathrm{C}_{4}$ atom of the nearest $\mathrm{C}_{1} \equiv \mathrm{C}-\mathrm{C} \equiv \mathrm{C}_{4}$ unit $(1,4$ topochemical polymerization involves connection between these two atoms) is $5.196 \AA$. This distance is much larger than the upper limit quoted by Baughman for $R_{1,4}$, i.e. $5 \AA$.., ${ }^{214}$ Furthermore, in this case, the two supposedly reacting $\mathrm{C}_{1} \equiv \mathrm{C}-\mathrm{C} \equiv \mathrm{C}_{4}$ rods would be nearly perpendicular when they should be more or less parallel.

Interestingly, water molecules are not disordered. Each molecule is kept in place tightly by eight hydrogen bonds (Figure 2). There are two strong $\mathrm{O}-\mathrm{H} \cdots \mathrm{N}$ interactions $\left(d(\mathrm{H} 11 \cdots \mathrm{N} 4)=1.986 \AA, d(\mathrm{O} 1 \cdots \mathrm{N} 4)=2.853 \AA, \angle \mathrm{O} 1-\mathrm{H} 11 \cdots \mathrm{N} 4=175.69^{\circ}\right.$, Table 2$)$ and six weaker $\mathrm{C}-\mathrm{H} \cdots \mathrm{O}$ interactions. The $\mathrm{O}-\mathrm{H} \cdots \mathrm{N}$ interactions of $\mathbf{2}$ are similar to that found in the $\mathrm{X}$ ray crystal structure of 4,4'-bis(imidazolyl)biphenyl monohydrate $(d(\mathrm{H} \cdots \mathrm{N})=1.987 \AA$, $\left.d(\mathrm{O} \cdots \mathrm{N})=2.862 \AA, \angle \mathrm{O}-\mathrm{H} \cdots \mathrm{N}=174.70^{\circ}\right) .{ }^{71,72}$ Geometrical parameters indicative of stronger $\mathrm{O}-\mathrm{H} \cdots \mathrm{N}$ interactions have been found in 2,6-bis(imidazol-1-yl)pyridine monohydrate ${ }^{73}$ $\left(d(\mathrm{H} \cdots \mathrm{N})=1.770 \AA, d(\mathrm{O} \cdots \mathrm{N})=2.799 \AA, \quad \angle \mathrm{O}-\mathrm{H} \cdots \mathrm{N}=167.61^{\circ}\right)$ and $1,1^{\prime}-(1,4-$ butanediyl)bis(2-phenylimidazole) $\operatorname{dihydrate}^{74}(d(\mathrm{H} \cdots \mathrm{N})=1.885 \AA, d(\mathrm{O} \cdots \mathrm{N})=2.804 \AA, \angle \mathrm{O}-$ $\left.\mathrm{H} \cdots \mathrm{N}=172.98^{\circ}\right)$. Geometrical parameters indicative of weaker $\mathrm{O}-\mathrm{H} \cdots \mathrm{N}$ interactions have been found in 1,2,4,5-tetrakis(1H-imidazol-1-ylmethyl)benzene tetrahydrate ${ }^{75}(d(\mathrm{H} \cdots \mathrm{N})=$ $2.019 \AA, d(\mathrm{O} \cdots \mathrm{N})=2.865 \AA, \angle \mathrm{O}-\mathrm{H} \cdots \mathrm{N}=165.18^{\circ}$ ) and 1,3,5-tris(imidazol-1-ylmethyl)2,4,6-trimethylbenzene monohydrate ${ }^{76}(d(\mathrm{H} \cdots \mathrm{N})=2.038 \AA, d(\mathrm{O} \cdots \mathrm{N})=2.931 \AA, \angle \mathrm{O}-\mathrm{H} \cdots \mathrm{N}$ $\left.=158.54^{\circ}\right)$. The six $\mathrm{C}-\mathrm{H} \cdots \mathrm{O}$ interactions may be divided into categories: two of them are $\mathrm{CH}_{2} \cdots \mathrm{O}$ interactions $(2 \times \mathrm{C} 7-\mathrm{H} 72 \cdots \mathrm{O} 1$, see Table 2$)$, and four of them are $\mathrm{C}_{\mathrm{im}}-\mathrm{H} \cdots \mathrm{O}(\mathrm{im}=$ imidazolyl) interactions $(2 \times \mathrm{C} 3-\mathrm{H} 31 \cdots \mathrm{O} 1$ and $2 \times \mathrm{C} 6-\mathrm{H} 61 \cdots \mathrm{O} 1)$. The latter four interactions involve hydrogen atoms borne by $\mathrm{C}-2$ and C-5 carbons of imidazolyl rings (see generic 
numbering scheme in Scheme 3); hydrogens borne by C-4 carbons do not interact with water molecules.

Close examination of the organic shell making up the cavity around the water molecule (Figure 3) indicates that the imidazole- $\mathrm{CH}_{2}$ part of the diacetylenic compound exhibits two types of hydrogen-bonding patterns. In the first pattern, the $\mathrm{C} 2-\mathrm{H}$ fragment of the imidazolyl ring and the $\mathrm{CH}_{2}$ group both interact with the water molecule. In the second pattern, the $\mathrm{C} 5-\mathrm{H}$ fragment of the imidazolyl ring interacts with the water molecule and the $\mathrm{CH}_{2}$ group interacts with a nearby imidazolyl nitrogen. Undoubtedly, this extra $\mathrm{CH}_{2} \cdots \mathrm{N}$ interaction increases the stability of the assembly. A detailed description of these hydrogen bonding interactions is provided in the Supporting Information.

Besides being involved in a hydrogen-bonding interaction with the water molecule (see Supporting Information), the $\mathrm{C} 5-\mathrm{H}$ bond of the imidazolyl ring is involved in a $\mathrm{C}-\mathrm{H} \cdots \pi$ interaction with a nearby imidazolyl ring (see C6-H61 $\cdots \mathrm{C} 5^{\mathrm{i}}$ and $\mathrm{C} 6-\mathrm{H} 61 \cdots \mathrm{C} 6^{\mathrm{i}}$ in Table 3). The C6-H61 bond does not interact symmetrically with the $\mathrm{C} 5^{\mathrm{i}}=\mathrm{C} 6^{\mathrm{i}}$ bond as indicated by the large difference between the H61 $\cdots \mathrm{C} 5^{\mathrm{i}}$ and H61 $\cdots \mathrm{C} 6^{\mathrm{i}}$ distances $\left(d\left(\mathrm{H} 61 \cdots \mathrm{C} 5^{\mathrm{i}}\right)=3.481 \AA\right.$ and $\left.d\left(\mathrm{H} 61 \cdots \mathrm{C} 6^{\mathrm{i}}\right)=3.034 \AA\right)$. A survey of the Cambridge Structural Database $(\mathrm{CSD})^{77}$ revealed twelve non-ionic, uncomplexed, imidazole-based compounds exhibiting a similar interaction: the minimum $\mathrm{C}-\mathrm{H} \cdots \mathrm{C}=\mathrm{C}$ value was $2.664 \AA$, the maximum value $2.899 \AA$, and the mean distance $2.804 \AA$. Thus, the $\mathrm{C} 6-\mathrm{H} 61 \cdots \mathrm{C} 5^{\mathrm{i}}=\mathrm{C} 6^{\mathrm{i}}$ interaction observed in $\mathbf{2}$ is weak.

Hydrogens borne by $\mathrm{C} 4$ carbons are involved in $\mathrm{C}-\mathrm{H} \cdots \pi$ interactions with neighboring $\mathrm{C} \equiv \mathrm{C}$ and $\mathrm{C}=\mathrm{C}$ groups. Geometrical parameters for the $\mathrm{C} 4-\mathrm{H} \cdots \mathrm{C}=\mathrm{C}$ interaction are listed in Table $3\left(\mathrm{C} 5-\mathrm{H} 51 \cdots \mathrm{C} 5^{\mathrm{i}}=3.458 \AA\right.$ and $\left.\mathrm{C} 5-\mathrm{H} 51 \cdots \mathrm{C} 6^{\mathrm{i}}=3.553 \AA\right)$. These distances are quite long by comparison with values reported in the literature. A survey of the Cambridge Structural Database $(\mathrm{CSD})^{77}$ revealed nine non-ionic, uncomplexed, imidazole-based compounds exhibiting a similar interaction: the minimum $\mathrm{C}-\mathrm{H} \cdots \mathrm{C}=\mathrm{C}$ value was $2.707 \AA$, the maximum value $2.897 \AA$, and the mean distance $2.832 \AA$. Thus, the $\mathrm{C} 5-\mathrm{H} 51 \cdots \mathrm{C} 5^{\mathrm{i}}=\mathrm{C} 6{ }^{\mathrm{i}}$ interaction observed in $\mathbf{2}$ is weak. Table 3 also contains geometrical parameters for the C4$\mathrm{H} \cdots \mathrm{C} \equiv \mathrm{C}$ interaction $\left(\mathrm{C} 5-\mathrm{H} 51 \cdots \mathrm{C} 8^{\mathrm{ii}}=2.944 \AA\right.$ and $\left.\mathrm{C} 5-\mathrm{H} 51 \cdots \mathrm{C} 9^{\mathrm{ii}}=3.003 \AA\right)$. On the basis of contact distances, it is evident that the $\mathrm{C} 4-\mathrm{H} \cdots \mathrm{C} \equiv \mathrm{C}$ interaction is much stronger than the $\mathrm{C} 4$ $\mathrm{H} \cdots \mathrm{C}=\mathrm{C}$ interaction. A survey of the Cambridge Structural Database $(\mathrm{CSD})^{77}$ revealed only one non-ionic, uncomplexed, imidazole-based compound exhibiting a similar interaction, namely dimethyl 7-(3-butynyl)-7-(4-pentynoyloxy)-7H-pyrrolo(1,2-a)imidazole-5,6dicarboxylate. $^{78,79}$ For this latter molecule, intermolecular $\mathrm{C} 4-\mathrm{H} \cdots \mathrm{C}_{\mathrm{sp}}$ distances amount to 
2.844 and 3.014 $\AA$. Thus, the $\mathrm{C} 4-\mathrm{H} \cdots \mathrm{C}_{\mathrm{sp}}$ distances observed in $\mathbf{2}$ are similar to those observed in dimethyl 7-(3-butynyl)-7-(4-pentynoyloxy)-7H-pyrrolo(1,2-a)imidazole-5,6-dicarboxylate, but unlike in the latter compound, the $\mathrm{C} 4-\mathrm{H}$ bond interacts in a nearly symmetrical fashion with the triple bond.

The topology of $\mathbf{2}$ is dictated by the strong hydrogen-bonding interaction between the water molecule and the diacetylenic compound. This interaction generates polymeric chains. When viewed down the crystallographic $b$ axis (Figure 4), the presence of two types of 1D chains is evident: one chain (green) runs parallel to one diagonal of the $a c$ face and the other chain (red) runs parallel to the other diagonal of that same face. The superposition of these two sets of 1D chains generates a grid with a diamond-shaped mesh. The mesh is narrow, $4.71 \AA \times 5.18 \AA$, resulting in a compact structure.

A survey of the Cambridge Structural Database $(\mathrm{CSD})^{77}$ revealed one non-ionic, uncomplexed, imidazole-based compound exhibiting 1D chains analogous to those found in 2, namely 4,4'-bis(imidazolyl)biphenyl monohydrate. ${ }^{71,72}$ The chains present in 4,4'bis(imidazolyl)biphenyl monohydrate, however, are not oriented orthogonally but are all parallel. Close examination of the crystal structure of this latter compound indicates that, in addition to strong interchain imidazole $\cdots \mathrm{H}_{2} \mathrm{O} \cdots$ imidazole interactions, there are sizeable C$\mathrm{H} \cdots \pi$ interactions between the $\mathrm{C} 5-\mathrm{H}$ bond of one imidazolyl ring and the $\pi$ cloud of a nearby phenyl group. Undoubtedly, these extra $\mathrm{C}-\mathrm{H} \cdots \pi$ interactions contribute to keeping the chains parallel. Such a combination of interactions is lacking from 2.

\section{Structure of 1,6-bis(1-benzimidazolyl)-2,4-hexadiyne (5)}

1,6-Bis(1-benzimidazolyl)-2,4-hexadiyne (5) crystallizes from dichloromethane as light brown crystals. The space group is monoclinic $P 2_{1} / c$ with $Z=4$ (Table 1); there is one molecule in the asymmetric unit. ${ }^{69}$ Unlike 1,6-bis(1-imidazolyl)-2,4-hexadiyne, diacetylene 5 crystallizes as an anhydrous form. This situation is reminiscent of the dichotomies that exist between 4,4'-bis(imidazolyl)biphenyl and 1,1'-biphenyl-4,4'-diylbis(1H-benzimidazole), and between 1,4-di(1-imidazolyl)butane and 1,1'-butane-1,4-diylbis(1H-benzimidazole). 4,4'Bis(imidazolyl)biphenyl ${ }^{71,72}$ crystallizes as a monohydrate and 1,4-di(1-imidazolyl)butane ${ }^{80}$ as a dihydrate, whereas 1,1'-biphenyl-4,4'-diylbis(1H-benzimidazole $)^{81,82}$ and 1,1'-butane-1,4diylbis(1H-benzimidazole $)^{83}$ both crystallize as anhydrous forms. It was thought originally that these dichotomies were the result of two joint contributions: first, the imine nitrogen of the imidazole ring is more basic than the imine nitrogen of the benzimidazole ring, ${ }^{57}$ so the 
formation of a hydrate in which the water molecule is hydrogen-bonded to the heterocycle is expected to be favored for imidazole-based compounds. Second, the less hydrophilic character of the benzimidazolyl moiety as compared with that of the imidazolyl group is anticipated to be another important factor. We have found, however, that another form of 5 exists, 4 (see below), that incorporates water molecules in the lattice. Consequently, the aforementioned arguments are probably not decisive and the actual reason for this situation most likely originates from crystal packing forces.

Water molecules are not present in the structure of $\mathbf{5}$ to connect the diacetylenic rods into infinite wires, yet the basic structure is still polymeric. Assembly of $\mathbf{5}$ into polymeric chains takes place through $\pi \cdots \pi$ interactions between benzimidazolyl groups (Figure 5); these interactions are supplemented by intermolecular $\mathrm{C}-\mathrm{H} \cdots \pi$ contacts. A detailed description of these interactions is provided in the Supporting Information.

When examining the structure down the crystallographic $b$ axis, it looks as if all of the chains were parallel. Yet, all of the chains are not identical and, in fact, there are two types of chains, shown in blue and green in Figure 6. Blue chains line up along the $c$ axis with a separation of $9.235 \AA$; these chains interact with one another through $\mathrm{C}-\mathrm{H} \cdots \mathrm{N}$ hydrogen bonds and $\mathrm{C}-\mathrm{H} \cdots \pi$ contacts (Figure 7 ). Interestingly, the acac-like hydrogen-bonding pattern previously observed in the crystal structure of $\mathbf{2}$ (see Supporting Information) is also present in the structure of 5. This time, the $\mathrm{C} 2-\mathrm{H}$ hydrogen of a benzimidazolyl ring and the $\mathrm{CH}_{2}$ group bound to that same ring point at the $\mathrm{N} 3$ nitrogen of a benzimidazole moiety (see generic numbering scheme in Scheme 3) located in a neighboring blue chain. The geometrical parameters of this acac-like interaction are as follows: $d(\mathrm{H} 201 \cdots \mathrm{N} 4)=2.480 \AA, d(\mathrm{C} 20 \cdots \mathrm{N} 4)$ $=3.248 \AA, \angle \mathrm{C} 20-\mathrm{H} 201 \cdots \mathrm{N} 4=139.26^{\circ} ; d(\mathrm{H} 151 \cdots \mathrm{N} 4)=2.654 \AA, d(\mathrm{C} 15 \cdots \mathrm{N} 4)=3.330 \AA$, $\angle \mathrm{C} 15-\mathrm{H} 151 \cdots \mathrm{N} 4=126.44^{\circ}$. Furthermore, the H201, C20, N16, C15, and H151 atoms lie nearly in the same plane.

The acac-like hydrogen-bonding pattern is supplemented by a $\mathrm{C}-\mathrm{H} \cdots \pi$ interaction: the $\mathrm{C} 2-\mathrm{H}$ hydrogen of the benzimidazolyl group from the second chain involved in the acac-like connection interacts with a phenyl carbon of a benzimidazole moiety located in the first chain (Figure 7). The geometrical parameters of this interaction are as follows: $d(\mathrm{H} 51 \cdots \mathrm{C} 23)=$ $2.844 \AA, d(\mathrm{C} 5 \cdots \mathrm{C} 23)=3.715 \AA, \angle \mathrm{C} 5-\mathrm{H} 51 \cdots \mathrm{C} 23=156.53^{\circ}$.

Blue chains interact with green chains through $\mathrm{C}-\mathrm{H} \cdots \pi$ contacts (Figure 8): the $\mathrm{C}-\mathrm{H}$ bond is that of a methylene group and the $\pi$ cloud belongs to the phenyl part of a benzimidazolyl moiety. The geometrical parameters for this interaction are: $d(\mathrm{H} 101 \cdots \mathrm{Cg})=$ 
$2.644 \AA, d(\mathrm{C} 10 \cdots \mathrm{Cg})=3.271 \AA$, and $\angle \mathrm{C} 10-\mathrm{H} 101 \cdots \mathrm{Cg}=121.93^{\circ}$. Thirty-two uncomplexed benzimidazole-based compounds were retrieved from the Cambridge Structural Database $(\mathrm{CSD})^{77}$ that exhibit a similar interaction in the solid state. For these compounds, the minimum $\mathrm{H} \cdots \mathrm{Cg}$ value was $2.578 \AA$, the maximum value $2.998 \AA$, and the mean distance $2.832 \AA$. Thus, the $\mathrm{CH}_{2} \cdots \pi$ interactions observed in $\mathbf{5}$ are fairly strong.

Blue chains are too far away from one another to undergo 1,4 topochemical polymerization: the $R_{1,4}$ distance is $7.000 \AA$, well beyond the $5 \AA$ limit quoted by Baughman. 2 , 14 The $R_{1,4}$ distance between blue chains and green chains, $4.290 \AA$, suggests that 1,4 topochemical polymerization is possible (shown as red dashed lines in Figure 9). But the angle, $\gamma$, between the polymerization axis (a fictive line that passes through the centroids of the reacting $\mathrm{C} \equiv \mathrm{C}-\mathrm{C} \equiv \mathrm{C}$ rods) and a straight line encompassing all of the carbons of the $\mathrm{C} \equiv \mathrm{C}$ $\mathrm{C} \equiv \mathrm{C}$ fragments also has to be right. According to Baughman, $\gamma$ should be near $45^{\circ} .{ }^{2,14}$ For a large number of polymerizable diacetylenes it is observed that the reacting $C \equiv C-C \equiv C$ units are parallel, so there is only one value for $\gamma$. In the case of $\mathbf{5}$, however, these units are not parallel, so there are two different $\gamma$ angles; these angles are respectively 42.1 and $62.4^{\circ}$. Because one of the $\gamma$ values differs significantly from $45^{\circ}$, it is not clear whether 1,4 polymerization will actually occur.

Such a situation is quite rare, and as far as we know, only one DA has been reported before that shows polymerization reactivity and has nonparallel reactive diacetylene groups in the crystal lattice. This DA is 2,4-hexadiyne-1,6-bis( $m$-tolylurethane), $\mathrm{HD}_{m} \mathrm{TU}$, in its "orange" (i.e. unsolvated) phase. ${ }^{19}$ In the X-ray crystal structure of this molecule, all of the reactive diacetylene groups are neither translationally related nor related by a center of inversion, but they are related by a glide plane. As a result, in the direction of polymerization, molecules are crossed at an angle of $72^{\circ}$. Close inspection of the structure indicates that this unusual arrangement is the consequence of intermolecular $\mathrm{N}-\mathrm{H} \cdots \mathrm{O}$ hydrogen bonding. This arrangement has been put forth as being responsible for the low overall rate of formation of polymer, $7-8 \%$ upon $\mathrm{X}$ irradiation and $35 \%$ upon irradiation with $\gamma$-rays.

\section{Structure of 1,6-bis(1-benzimidazolyl)-2,4-hexadiyne monohydrate (4)}

The cream-white solid isolated after chromatographic purification and slow evaporation of the solvents to dryness is not 5 but its monohydrate $\mathbf{4}$. This was confirmed by elemental analysis and infrared spectroscopy. Several attempts were made to obtain single crystals of this form, but these efforts were unsuccessful. Eventually, a structural analysis of the solid by powder 
X-ray diffraction was undertaken. Experimental details of data collection and information concerning structure solution and refinement can be found in the Experimental Section.

Monohydrate 4 crystallizes in the monoclinic space group $P 2_{1}$ with $Z=4$; there are two diacetylene molecules in the asymmetric unit and two water molecules. ${ }^{69}$ The structure of $\mathbf{4}$ is quite different from that of $\mathbf{5}$ in that diacetylene molecules now pile up in stacks; the two crystallographically unique stacks are shown in green and blue in Figure 10. When looking at the structure down the $a$ axis, two types of regions are evident between stacks, polar regions that contain water molecules, and non-polar ones where hydrophobic interactions, notably C$H \cdots \pi$ contacts, are important.

Unlike the situation found in $\mathbf{2}$, water molecules are not isolated but interact with one another. They form ribbons that run parallel to the $a$ direction (Figure 10). One such ribbon is shown in Figure 11. Intermolecular $\mathrm{O} \cdots \mathrm{H}$ distances amount to 1.974 and $2.352 \AA$, and associated $\mathrm{O}-\mathrm{H} \cdots \mathrm{O}$ angles are 135.43 and $140.76^{\circ}$, respectively. Water ribbons interact with benzimidazolyl groups through $\mathrm{O}-\mathrm{H} \cdots \mathrm{N}$ hydrogen bonds. Four types of $\mathrm{O}-\mathrm{H} \cdots \mathrm{N}$ distances are found, 2.004, 2.013, 2.033, and $2.048 \AA$. On the basis of distances, the $\mathrm{O}-\mathrm{H} \cdots \mathrm{N}$ interactions of $\mathbf{4}$ appear to be weaker than those observed in $\mathbf{2}$. One comment must be made, however, concerning the $\mathrm{O}-\mathrm{H} \cdots \mathrm{N}$ interaction associated with the $2.033 \AA$ distance: this interaction is probably not a true $\mathrm{O}-\mathrm{H} \cdots \mathrm{N}$ hydrogen bond but more likely an $\mathrm{O}-\mathrm{H} \cdots \pi$ interaction: the $\mathrm{O}-\mathrm{H} \cdots \mathrm{Cg}$ distance $(\mathrm{Cg}$ is the centroid position of the $\mathrm{N} 1-\mathrm{C} 2-\mathrm{C} 3-\mathrm{N} 4-\mathrm{C} 5 \mathrm{ring}$ ) is $2.220 \AA$ and the $\mathrm{O}-\mathrm{H} \cdots \mathrm{Cg}$ angle $166.33^{\circ}$. These $\mathrm{O}-\mathrm{H} \cdots \mathrm{N} / \mathrm{O}-\mathrm{H} \cdots \pi$ interactions are supplemented by two $\mathrm{C}-\mathrm{H} \cdots \mathrm{OH}_{2}$ interactions involving the $\mathrm{C}-\mathrm{H}$ bond located between the nitrogen atoms of the N1-C2-C3-N4-C5 imidazolyl group (see Figure 11). The geometrical parameters for these interactions are: $d(\mathrm{H} 51 \cdots \mathrm{O} 6)=2.119 \AA, d(\mathrm{C} 5 \cdots \mathrm{O} 6)=2.369 \AA, \angle \mathrm{C} 5$ $\mathrm{H} 51 \cdots \mathrm{O} 6=93.16^{\circ}$, and $d(\mathrm{H} 51 \cdots \mathrm{O} 12)=2.176 \AA, d(\mathrm{C} 5 \cdots \mathrm{O} 12)=2.722 \AA, \angle \mathrm{C} 5-\mathrm{H} 51 \cdots \mathrm{O} 12=$ $115.39^{\circ} . \mathrm{C}-\mathrm{H} \cdots \mathrm{OH}_{2}$ interactions between the hydrogen atom borne by the $\mathrm{C} 44$ carbon of the N40-C41-C42-N43-C44 imidazolyl group (located in the facing stack) and O6 are weak, as suggested by the rather large H441… O6 separation, $2.611 \AA$. Lastly, the acac-like behavior of the imidazole- $\mathrm{CH}_{2}$ fragment observed previously in the structures of $\mathbf{2}$ and $\mathbf{5}$ is not detected in the structure of 4 .

Cohesion of the structure is also ensured by numerous $\mathrm{C}-\mathrm{H} \cdots \pi$ interactions. There are ten $\mathrm{C}_{\text {phenyl }}-\mathrm{H} \cdots \mathrm{C}_{\text {phenyl }}$ interactions with $\mathrm{H} \cdots \mathrm{C}_{\text {phenyl }}$ distances spanning the range $2.281-2.948 \AA$ and eight $\mathrm{C}_{\text {phenyl }}-\mathrm{H} \cdots \mathrm{C}_{\mathrm{sp}}$ interactions with $\mathrm{H} \cdots \mathrm{C}_{\mathrm{sp}}$ distances in the range 2.176-3.032 $\AA$. There is one $\mathrm{C}-\mathrm{H} \cdots \pi$ interaction involving the $\mathrm{C} 2-\mathrm{H}$ fragment of a benzimidazolyl moiety (see 
generic numbering scheme in Scheme 3); this fragment interacts with a nearby phenyl ring, and associated contact distances are $d(\mathrm{H} 291 \cdots \mathrm{C} 22)=2.101 \AA$ and $d(\mathrm{H} 291 \cdots \mathrm{C} 23)=2.141 \AA$. $\mathrm{CH}_{2}$ groups also participate in quite a few $\mathrm{C}-\mathrm{H} \cdots \pi$ interactions: there are eight $\mathrm{CH}_{2} \cdots \mathrm{C}_{\text {phenyl }}$ interactions with $\mathrm{H} \cdots \mathrm{C}_{\text {phenyl }}$ distances spanning the range $2.351-2.987 \AA$ and eight $\mathrm{CH}_{2} \cdots \mathrm{C}_{\mathrm{sp}}$ interactions with $\mathrm{H} \cdots \mathrm{C}_{\mathrm{sp}}$ distances in the range 2.116-3.069 $\AA$.

As previously observed in $\mathbf{5}$, the structure of $\mathbf{4}$ exhibits several $\pi \cdots \pi$ interactions between benzimidazolyl groups (Figure 12). Unlike 5, however, these interactions are

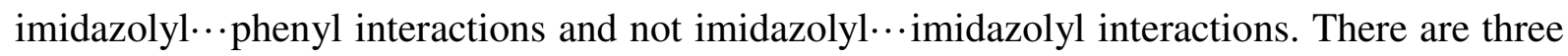
imidazolyl...phenyl interactions with $\mathrm{Cg}$... Cg distances smaller than $4 \AA$. Geometrical parameters for these interactions are listed in Table 4. On the basis of distances and angles, the imidazolyl...phenyl interactions of $\mathbf{4}$ seem to be a little stronger than the imidazolyl...imidazolyl interactions of $\mathbf{5}$, albeit the difference is not large. A survey of the Cambridge Structural Database $(\mathrm{CSD})^{84}$ revealed twenty-three benzimidazole-based compounds with $\mathrm{Cg}($ imidazolyl $) \cdots \mathrm{Cg}$ (phenyl) distances smaller than $4.0 \AA$ : the minimum Cg $\cdots \mathrm{Cg}$ value was $3.504 \AA$, the maximum value $3.991 \AA$, and the mean distance $3.783 \AA$. Thus, the $\pi \cdots \pi$ interactions observed in $\mathbf{4}$ are fairly strong.

The $R_{1,4}$ distance in green stacks (see Figure 10) is $4.051 \AA$, the translational period d is $4.538 \AA$, and the $\gamma$ angle is $57.09^{\circ}$. The $R_{1,4}$ distance in blue stacks is $3.086 \AA$, the translational period $\mathrm{d}$ is $4.538 \AA$, and the $\gamma$ angle is $43.52^{\circ}$. Consequently, although both $\mathrm{d}$ distances lie outside the range given by Baughman, ${ }^{2,14}$ the situation found in blue stacks is a lot more favorable to topochemical diacetylene polymerization than that encountered in green stacks. Furthermore, inter-stack polymerization cannot be ruled out completely. The translational period $\mathrm{d}$ is quite long, $7.176 \AA$, but the $R_{1,4}$ distance meets Baughman's criteria, $4.778 \AA$ A. As in the case of $\mathbf{5}$, possibly reacting molecules are not parallel and are crossed at an angle of $18.77^{\circ}$ in the direction of polymerization. Consequently, two different $\gamma$ angles exist between the polymerization axis and straight lines encompassing the carbons of the reacting $\mathrm{C} \equiv \mathrm{C}-\mathrm{C} \equiv \mathrm{C}$ fragments, 41.26 and $33.65^{\circ}$. Here again, one angle meets Baughman's criteria and the other does not.

In summary, water molecules bind strongly to 1,6-bis(1-imidazolyl)-2,4-hexadiyne (1) and are necessary for a crystalline material to be obtained, 2. On the other hand, 1,6-bis(1benzimidazolyl)-2,4-hexadiyne can be obtained in both hydrate (4) and anhydrate (5) forms. In these materials, cohesion is mostly ensured by hydrophobic interactions, but these interactions are overpowered by hydrophilic interactions when water molecules are present, 
which leads to a reorganization of the crystal. In this respect, these diacetylenes may be compared to proteins for which it is observed that the secondary structure is governed by hydration. ${ }^{85}$ Furthermore, similarly to the fact that hydration determines the structural stability of proteins, ${ }^{86}$ we have found that the presence of water is essential to stabilize $\mathbf{1}$. Removal of water from 2 does not lead to amorphization of the solid but to its decomposition. This phenomenon may be regarded as being similar to protein denaturation. But hydration also governs the flexibility and the function of proteins; ${ }^{86}$ we have found that a similar situation exists concerning $\mathbf{5}$ and that the presence of water changes the polymerization reactivity of this compound. These aspects are discussed in the following paragraphs.

\section{Solid-state stability of 2}

White crystals of 2 were irradiated at $254 \mathrm{~nm}$ for 5 days. The crystals took a light brown shade presumably because of surface decomposition, but no color change to red or blue was noticed. Furthermore, the Raman spectrum of the irradiated crystals showed only the stretching vibration of the monomer, $\tilde{v}=2267 \mathrm{~cm}^{-1}$. Therefore, diacetylene polymerization did not occur. These observations agree with the X-ray crystal structure of $\mathbf{2}$ that shows that water molecules hold the diacetylene units in place tightly and prevent them from polymerizing.

Attempts have been made to render this DA reactive by removal of the water molecules. ${ }^{87}$ A DSC analysis of $\mathbf{2}$ showed that water goes away at a temperature slightly less than $100{ }^{\circ} \mathrm{C}$ (see Figure S3 in the Supplementary Material). Thus, 2 was heated to $110{ }^{\circ} \mathrm{C}$ in air. The white crystals turned rapidly into a black solid. An analysis of the solid by Raman spectroscopy showed only fluorescence; neither the band of the monomer (vide supra) nor those of a PDA $\left(\tilde{v} \sim 1500 \mathrm{~cm}^{-1}\right.$ and $\left.\tilde{v} \sim 2100 \mathrm{~cm}^{-1}\right)$ were observed. Problems due to high fluorescence are frequently encountered during the characterization of carbon-rich materials by Raman spectroscopy; Goroff and colleagues have come across similar difficulties while

analyzing poly(diiododiacetylene) fibers. ${ }^{39}$ An X-ray powder diffraction (XRPD) analysis of the black material gave a diffractogram that exhibits a broad peak at $2 \theta \approx 22^{\circ}$ (Figure 13c). Peaks corresponding to the monomer were not detected. Similar broad peaks have been observed previously in the powder patterns of graphite-like materials obtained by thermal decomposition of ionic liquids and polymers. ${ }^{88-90}$

The infrared spectrum of the black solid is presented in Figure 14d. It shows that the intensities of the bands due to water around $3200 \mathrm{~cm}^{-1}$ have decreased significantly. The loss 
of water was confirmed by elemental analysis that showed that the amount of residual oxygen in the solid was $1.236 \%$ (see Table 5); the oxygen content of the monomer is $7.01 \%$. In addition, the growth of a new band is noticed at $\tilde{v} \sim 1600 \mathrm{~cm}^{-1}$. This band is absent from the IR spectrum of the monomer. In previous work on the polymerization of silicon-containing diacetylenes, we have observed that molten-state polymerization of $\mathrm{Me}_{3} \mathrm{SiCH}_{2} \mathrm{C} \equiv \mathrm{CC} \equiv \mathrm{CCH}_{2} \mathrm{SiMe}_{3}$ gave a dark brown powder with a metallic luster. The IR spectrum of this brown solid exhibited a broad band at $\tilde{v}=1594 \mathrm{~cm}^{-1}$ which was assigned to the formation of polyaromatic-like species with $\mathrm{CH}_{2} \mathrm{SiMe}_{3}$ dangling groups. ${ }^{91}$ We believe that the black solid resulting from the heat treatment of 2 at $110{ }^{\circ} \mathrm{C}$ has a similar structure, i.e. it is a polyaromatic-like species with $\mathrm{CH}_{2}$-imidazol dangling groups.

The cross-polarization magic-angle spinning (CP/MAS) ${ }^{13} \mathrm{C}$ NMR spectrum of the black powder is presented in Figure 15d. It shows that the resonances corresponding to the triple bonds of $2, \delta=67.5$ and $74.5 \mathrm{ppm}$ (Figure 15a), have disappeared completely. Also, the methylene resonance of $\mathbf{2}$ at $\delta=36.9 \mathrm{ppm}$ has been replaced by a very broad resonance centered at $43 \mathrm{ppm}$. Lastly, the narrow signals corresponding to the imidazolyl carbons of 2 ( $\delta$ $=119.9,128.5$, and $139.3 \mathrm{ppm}$ ) have been replaced by a broad resonance centered at 130 ppm. This broad resonance seems to be the sum of two contributions: sharper signals stemming from imidazolyl groups and a broad resonance due to polyaromatic-like species. These observations are similar to those that were made concerning the dark brown powder resulting from molten-state polymerization of $\mathrm{Me}_{3} \mathrm{SiCH}_{2} \mathrm{C} \equiv \mathrm{CC} \equiv \mathrm{CCH}_{2} \mathrm{SiMe}_{3}{ }^{91}$ The solidstate ${ }^{13} \mathrm{C}$ NMR spectrum of the powder exhibited a broad resonance at $22 \mathrm{ppm}$ due to $\mathrm{CH}_{2}$ groups and a broad resonance at $130 \mathrm{ppm}$ due to aromatic carbons. A fairly sharp resonance was also observed at $0 \mathrm{ppm}$ corresponding to $\mathrm{SiMe}_{3}$ groups. The $\mathrm{CP} / \mathrm{MAS}{ }^{13} \mathrm{C} \mathrm{NMR}$ spectrum of $\mathrm{Me}_{3} \mathrm{SiCH}_{2} \mathrm{C} \equiv \mathrm{CC} \equiv \mathrm{CCH}_{2} \mathrm{SiMe}_{3}$ exhibits one signal at $-2.0 \mathrm{ppm}\left(\mathrm{SiMe}_{3}\right)$, one signal at 7.9 ppm $\left(\mathrm{CH}_{2}\right)$, and two signals at 65.2 and $74.9 \mathrm{ppm}(\mathrm{C} \equiv \mathrm{C}){ }^{92}$

Thus, dehydration of $\mathbf{2}$ by heating does not induce a single-crystal to single-crystal transformation nor does it lead to amorphization, but decomposition into polyaromatic-like species is observed instead. This phenomenon corresponds to the early stage of a complex process that leads ultimately to nitrogen-doped graphitic materials. ${ }^{93}$

Confirmation that the decomposition of $\mathbf{2}$ is induced by dehydration and not by heat was obtained from the following experiments. In a first experiment, solvate $\mathbf{2}$ was evacuated at room temperature for $15 \mathrm{~h}$ under a vacuum of $0.1 \mathrm{mbar}$; a brown powder was recovered. In a second experiment, solvate 2 was evacuated under a vacuum of $5 \times 10^{-2}$ mbar, at room 
temperature, for the same amount of time; a brownish black solid was obtained. The oxygen content of the brown solid was $4.236 \%$ and that of the black solid $3.245 \%$ (Table 5). The infrared spectra of these solids (Figures 14b and 14c) both exhibit a decrease in the intensity of the band due to water $\left(\tilde{v} \sim 3200 \mathrm{~cm}^{-1}\right)$, and in each spectrum, a new band is observed at $\tilde{v} \sim$ $1600 \mathrm{~cm}^{-1}$. These results are in line with those described previously for the sample heated to $110{ }^{\circ} \mathrm{C}$. In the CP/MAS ${ }^{13} \mathrm{C}$ NMR spectrum of the brown solid (Figure 15b), a new resonance is visible at $\delta \sim 47 \mathrm{ppm}$ that is accompanied by sharp resonances due to residual 2 . Concerning the CP/MAS ${ }^{13} \mathrm{C}$ NMR spectrum of the black solid (Figure 15c), it is nearly identical to that obtained for the sample heated to $110{ }^{\circ} \mathrm{C}$ (vide supra), except for the imidazolyl signals that are sharper.

One example has been reported in the literature that relates the instability of the DA part of a DA-containing solvate upon removal of the solvent, and another example that relates the instability of the PDA part of a PDA-containing host-guest complex upon removal of the host. The first example was reported by Bunz and his group. ${ }^{94}$ These workers have observed that $\quad\left(\eta^{5}-2,4-c y c l o p e n t a d i e n-1-y l\right)[(1,2,3,3 a, 23 a-\eta)-4,5,6,7,12,13,14,15,20,21,22,23-$ dodecadehydro-3aH-dibenzo[ $[a, g]$ cyclopenta $[m]$ cyclooctadecen-3a-yl $]$ iron(II), a ferrocenefused dehydro[18]annulene, underwent explosive decomposition to soot containing a high content of onion-like carbon nanostructures upon loss of crystal solvent (dichloromethane/hexanes). The second example was described by Goroff and co-workers. ${ }^{39}$ These researchers have observed that removal of the host from a poly(diiododiacetylene) $N, N^{\prime}$-(bisheptanenitrile) oxalamide cocrystal gave poly(diiododiacetylene) fibers that were unstable. These fibers decompose into carbonaceous materials under certain conditions such as shock, pressure, or irradiation, but are quite stable when incorporated in a cocrystal.

\section{Polymerization reactivity of 5}

Brown crystals of 5 were heated to $106{ }^{\circ} \mathrm{C}$ for ten days with concomitant irradiation at 254 $\mathrm{nm}$. The crystals became slightly darker presumably because of surface decomposition, but no color change to red or blue was noticed. A Raman analysis of the crystals showed the band corresponding to the diacetylene monomer $\left(\tilde{v}=2266 \mathrm{~cm}^{-1}\right)$, but new bands around 1500 and $2100 \mathrm{~cm}^{-1}$ were not observed, consistent with the absence of an enyne structure. To confirm these results, a solid-state ${ }^{13} \mathrm{C}$ NMR analysis of the crystals was performed that showed the absence of signals corresponding to a polymer (see below). 


\section{Polymerization reactivity of 4}

Irradiation of $\mathbf{4}$ was carried out as described in the Experimental Section. A bluish gray solid was obtained after an irradiation period of three days, a color that is typically observed when a PDA is present. The solid was transferred in the thimble of a Soxhlet extractor and washed for three days with dichloromethane to remove unreacted monomer. A brownish powder was recovered which was characterized by spectroscopic methods and X-ray diffraction (see following paragraphs). As observed for most PDAs, poly-4 is insoluble in common laboratory solvents including water; consequently, its molecular weight could not be determined by size exclusion chromatography (SEC).

In the solid-state ${ }^{13} \mathrm{C}$ NMR spectrum of the washed powder, the signals corresponding to the triple bonds of the monomer ( $\delta=68-74 \mathrm{ppm}$ ) are no longer observed and have been replaced by two new resonances at 103 and $128 \mathrm{ppm}$ (Figure 16). These new signals indicate the presence of a PDA with an enyne structure. ${ }^{61,95}$ Furthermore, as observed previously by Sandman and co-workers in the case of poly-ETCD (ETCD = bis(ethyl)urethane of 5,7dodecadiyne-1,12-diol), ${ }^{95}$ poly-IPUDO (IPUDO = bis(isopropyl)urethane of 5,7-dodecadiyne1,12-diol) ${ }^{95}$ and poly- $p$ TS $\left(p\right.$ TS $=2,4$-hexadiyne-1,6-diol bis( $p$-toluenesulfonate) ${ }^{61}$ the resonance of the methylene groups adjacent to the triple bonds in the starting monomer has moved downfield by $10 \mathrm{ppm}$ in the spectrum of the polymer. This shift is consistent with the fact that shielding of the $\mathrm{CH}_{2}$ groups in the monomer by the nearby triple bonds no longer exists in the polymer.

The Raman spectrum of the solid is shown in Figure S4 of the Supplementary Material. It exhibits one intense line at $1468 \mathrm{~cm}^{-1}$ corresponding to the double bond of the polymer and another line at $2091 \mathrm{~cm}^{-1}$ corresponding to the triple bond. These Raman shifts are indicative of a blue phase PDA. ${ }^{96}$ In the Raman spectra of red phase PDAs, $v(C=C)$ bands are generally observed above $1500 \mathrm{~cm}^{-1}$ and $v(C \equiv C)$ bands above $2100 \mathrm{~cm}^{-1} \cdot{ }^{96}$

The fact that poly-4 is a blue phase PDA was confirmed by ultraviolet-visible (UVvis) absorption spectroscopy: a broad band is observed that extends to about $650 \mathrm{~nm}$ (see Figure S5 of the Supplementary Material). Red phase PDAs typically show absorption thresholds near $550 \mathrm{~nm}$ and blue phase PDAs near $640 \mathrm{~nm} .{ }^{96}$

The X-ray powder pattern of the irradiated material was recorded before and after Soxhlet extraction. The diffractogram of the unwashed material is shown in Figure 17b. It exhibits diffraction lines that are comparable to those of the nonpolymerized sample (Figure 17a). This is consistent with the fact that about $70 \%$ monomer is still present in the solid. The 
diffractogram of the Soxhlet extracted material is shown in Figure 17c. It shows that a loss of crystallinity has occurred during the washing step: sharp peaks are no longer visible and broad lines are observed at $2 \theta \approx 15.1^{\circ}, 21.5^{\circ}$, and $26.1^{\circ}$.

The amounts of water present in the washed and unwashed samples were determined by thermogravimetric analyses (TGA). The amount of water in the unwashed sample is $2.75 \%$, and that in the washed sample $2.74 \%$. Infrared spectroscopy (see Figure S6 in the Supplementary Material) confirms the presence of water in both solids. The amount of water present in the unwashed material is roughly half of that present in $\mathbf{4}, 5.5 \%$. As a result, some water appears to have been lost during the polymerization process; it is unclear whether this is the reason why the extent of polymerization is only $30 \%$.

The presence of water in poly- $\mathbf{4}$ is in line with the results obtained by Ouyang et al.: ${ }^{30}$ these workers have discovered that penta-2,4-diynyl 3,5-dihydroxybenzoate monohydrate polymerizes to a PDA that incorporates water in its lattice. Yet, our X-ray results disagree with what is typically observed when dealing with a topochemical polymerization process: in general, it is found that the cell parameters of the polymer are close to those of the monomer and the space group of the polymer is the same as that of the monomer. ${ }^{16,97}$ However, a few exceptions are known for which it is observed that polymerization generates a polymer that is amorphous to X-rays after extraction of the remaining monomer: such a situation was encountered during the polymerization of 2,4-hexadiyne-1,6-diol ${ }^{15}$ and during that of modification I of 2,4-hexadiyne-1,6-diol bis(phenylurethane). ${ }^{26}$ Thus, it is possible that amorphization of poly-4 originates from the removal of the unreacted monomer. On the other hand, this observation is a clear indication that solid-state polymerization of $\mathbf{4}$ proceeds in a homogeneous manner. ${ }^{26}$

Attempts were made to convert the amorphous polymer into a crystalline material: in a first experiment, the polymer was placed in a closed vessel containing water and left in contact with water vapor for 6 days. A powder X-ray diffraction analysis indicated that the material remained amorphous. In a second experiment, poly-4 was annealed at $120{ }^{\circ} \mathrm{C}$ overnight under argon, a procedure analogous to that previously employed for the polymer of modification I of 2,4-hexadiyne-1,6-diol bis(phenylurethane). ${ }^{26}$ Here again, no sharp diffraction peaks were observed in the diffractogram. 


\section{Conclusions}

The syntheses of thus far unknown 1,6-bis(1-imidazolyl)-2,4-hexadiyne (1) and of previously reported 1,6-bis(1-benzimidazolyl)-2,4-hexadiyne (5) have been described. The methodology consists in refluxing excess imidazole and benzimidazole with $p \mathrm{TS}$, a procedure that has been used in the past for the preparation of diacetylenes with diethylamino groups, ${ }^{62}$ but which, as far as we know, has never been employed for the syntheses of imidazole- and benzimidazolecontaining diacetylenes. It is a viable alternative to the widely used Hay coupling protocole, especially if the substituents of the target diyne are capable of deactivating the copper catalyst by complexation. We anticipate that this methodology should be amenable to the preparation of other types of azole-containing diacetylenes.

We have found that the benzimidazole-containing compound can be crystallized with water molecules (4) or without (5), whereas for the imidazole-containing diyne, water is essential to get a crystalline material (2). Structural characterization by X-ray crystallography has provided information on the way these molecules self-assemble in the absence of water, and how this arrangement is modified when water is present. Also, these investigations have allowed us to identify some of the similarities and differences that exist between imidazolyl and benzimidazolyl groups in terms of crystal packing. For example, the crystal structure of 2 has revealed the way the organic fragments organize around the water molecule and interact with it through an acac-like hydrogen-bonding pattern. Despite the absence of water, this hydrogen-bonding pattern is maintained in the structure of $\mathbf{5}$, with benzimidazole nitrogens replacing water oxygens. Yet, it is absent from the structure of $\mathbf{4}$ even though water is present. Interestingly, in this latter compound, water molecules are not isolated but are organized as ribbons, which could explain the dichotomy. Also, the structures of $\mathbf{4}$ and $\mathbf{5}$ do not exhibit the same $\pi-\pi$ interactions: in the case of 4 , imidazolyl $\cdots$ phenyl $\pi-\pi$ interactions are observed, whereas in the case of $\mathbf{5}$, imidazolyl $\cdots$ imidazolyl $\pi-\pi$ interactions are noticed. Surprisingly, $\pi$ $\pi$ interactions are not detected in the structure of 2 .

A fair number of drugs contain imidazolyl and benzimidazolyl substituents, notably theophylline, ornidazole, astemizole, emedastine, cimetidine, imoproxifan, and ciproxifan. ${ }^{98}$ In case it is necessary to improve the physical properties (solubility, hygroscopicity, stability, dissolution rate, bioavailability), mechanical properties (Young's modulus), or powder handling characteristics (particle size, flow, filterability) of these drugs by making cocrystals or solvates, structural information like the one reported here may turn out to be pivotal. 
Interestingly enough, in a recent publication, Aakeröy and his group have investigated the effect of water molecules in stabilizing cocrystals of pharmaceutical ingredients. ${ }^{99}$ In another area, the structural information derived from the crystallographic studies of $\mathbf{2}, \mathbf{4}$, and $\mathbf{5}$ is anticipated to be important to understand the structures of large biomolecules such as peptidomimetics and help predicting the interactions of these molecules with enzymes. ${ }^{100}$

In terms of crystal engineering, this study shows that it is possible to use water, and more generally solvent molecules, to transform a nonreactive diacetylene into a reactive one. Previous studies describing a similar approach are quite scarce. ${ }^{19,}{ }^{30}$ Indeed, trying to visualize the structure of a solvate in which the diacetylene fragments would be oriented suitably for topochemical polymerization is a hard thing to do, mostly because intermolecular interactions between solvent molecules are difficult to predict. In the cocrystal approach, intermolecular interactions between urea groups and oxalamide groups are well-established. ${ }^{29,31,101}$ Yet, the solvate approach is simple to implement, quite versatile because of the large range of solvents available, and one does not face the problem of having to remove the host in case one needs to recover the polymer. Beyond the polymerization aspect, this work also shows that water molecules can be important to stabilize structures that otherwise would be unstable. However, these solvent-containing assemblies are so stable that any attempt to modify their organization leads inevitably to decomposition. In this respect, diacetylenic fragments have proven to be excellent probes to evaluate the thermal stability of azole 2.

Work is currently in progress to study the organization of these diacetylenes with other hydrogen-bond donors, prepare coordination compounds with transition metals, and investigate their use as molecular precursors to nitrogen-doped graphitic materials. 


\section{Experimental section}

\section{Spectroscopic and characterization methods}

Solution ${ }^{1} \mathrm{H}$ and ${ }^{13} \mathrm{C}$ NMR spectra were obtained on a Bruker AVANCE DPX 200 instrument. ${ }^{1} \mathrm{H}$ chemical shifts were referenced to the proton impurity of the NMR solvent and ${ }^{13} \mathrm{C}$ chemical shifts to the NMR solvent. All of the ${ }^{13} \mathrm{C}$ magic-angle spinning (MAS) NMR spectra, except that of poly-4, were recorded at $100.62 \mathrm{MHz}$ on a Varian VNMRS 400 spectrometer operating at 9.4 T, with use of a $3.2 \mathrm{~mm}$ Varian T3 HXY MAS probe. Crosspolarization $(\mathrm{CP})$ with ramping of the ${ }^{1} \mathrm{H}$ rf field during the contact pulse was employed, followed by TPPM decoupling during acquisition. A 50-kHz sweep width, a contact time of 1 $\mathrm{ms}$, and a recycle delay time of $5 \mathrm{~s}$ were used. About $20 \mathrm{mg}$ of sample was spun at $13.5 \mathrm{kHz}$ in zirconia rotors. The CP/MAS ${ }^{13} \mathrm{C}$ NMR spectrum of poly-4 was recorded at $150.84 \mathrm{MHz}$ on a Varian VNMRS 600 spectrometer operating at $14.1 \mathrm{~T}$, with use of a $3.2 \mathrm{~mm}$ Varian T3 HXY MAS probe. The spinning speed was $20 \mathrm{kHz}$. Chemical shifts were referenced to an external sample of adamantane (high frequency peak at $\delta=38.5 \mathrm{ppm}$ ). Infrared spectra were recorded with a $4 \mathrm{~cm}^{-1}$ resolution on a Thermo Nicolet Avatar 320 FT-IR spectrometer, with use of the Attenuated Total Reflectance (ATR) sampling technique (diamond crystal). UV-vis absorption spectra were measured on a JASCO Model V-670 spectrometer with a 200-1000 $\mathrm{nm}$ scan range, a scan rate of $400 \mathrm{~nm} / \mathrm{min}$, and a resolution of $2 \mathrm{~nm}$. Samples were diluted with $\mathrm{BaSO}_{4}$. Raman spectra were measured at room temperature on a Bruker RFS100 FT spectrometer equipped with a continuous YAG laser $(\lambda=1064 \mathrm{~nm})$ as a light source and a germanium detector. ESI mass spectra were recorded on a Micromass QTOF spectrometer. Coupled TGA-DSC experiments were carried out under flowing nitrogen $(125 \mathrm{~mL} / \mathrm{min})$ on a TA Instruments SDT 2960 Simultaneous DSC-TGA apparatus with a heating rate of 10 ${ }^{\circ} \mathrm{C} / \mathrm{min}$. X-ray powder patterns were obtained on a PANAlytical Xpert-PRO diffractometer using $\mathrm{Ni}$-filtered $\mathrm{Cu} \mathrm{K} \alpha$ radiation. $\mathrm{C}, \mathrm{H}, \mathrm{N}, \mathrm{O}$ elemental analyses were performed in-house using a Thermo Finnigan FLASH EA 1112 Series analyser.

\section{Materials}

The chemicals used in this study were obtained from the following commercial sources: imidazole (Avocado), benzimidazole (Acrōs Organics), silanized silica gel (Merck), Geduran $^{\circledR}$ Si 60 silica gel (VWR). Solvents were purchased from the following suppliers: $\mathrm{CH}_{2} \mathrm{Cl}_{2}$ (Aldrich), anhydrous $\mathrm{CH}_{3} \mathrm{CN}$ (Aldrich), methanol (Aldrich), pentane (VWR). 2,4- 
Hexadiyne-1,6-diol bis(p-toluenesulfonate), $p$ TS (3), was made from 2,4-hexadiyne-1,6-diol according to a known procedure. ${ }^{61}$ 2,4-Hexadiyne-1,6-diol was prepared by oxidative dimerization of propargyl alcohol following reported protocols. ${ }^{102,103}$

\section{General considerations}

All of the syntheses involving air-sensitive materials were carried out under an inert atmosphere of argon using standard Schlenk-line techniques. Prior to use, $\mathrm{CH}_{2} \mathrm{Cl}_{2}$ was refluxed over and distilled from $\mathrm{P}_{2} \mathrm{O}_{5}$.

\section{Synthesis of 1,6-bis(1-imidazolyl)-2,4-hexadiyne monohydrate (2)}

A 4 g portion of $\mathbf{3}(9.45 \mathrm{mmol})$ was placed in a Schlenk flask and dissolved in $50 \mathrm{~mL}$ of dry $\mathrm{CH}_{2} \mathrm{Cl}_{2}$. To this solution was added a $2.59 \mathrm{~g}$ portion of imidazole (38.1 mmol, 4 equiv) dissolved in $50 \mathrm{~mL}$ of dry $\mathrm{CH}_{2} \mathrm{Cl}_{2}$. The mixture was stirred under reflux for $24 \mathrm{~h}$. After cooling to room temperature, the organic layer was washed with water $(4 \times 20 \mathrm{~mL})$, dried over magnesium sulfate, and the solvent was removed on a rotary evaporator. The residue was chromatographed on silanized silica gel with use of a 94:6 v/v $\mathrm{CH}_{2} \mathrm{Cl}_{2}-\mathrm{CH}_{3} \mathrm{OH}$ mixture as the eluent. Slow concentration of the fractions containing the desired product to dryness afforded white crystals of $2(1.1 \mathrm{~g}, 55 \%) .{ }^{1} \mathrm{H}$ NMR (200.1 MHz, DMSO- $\left.d_{6}\right): \delta 3.35$ (s, 2H, $\left.\mathrm{H}_{2} \mathrm{O}\right) ; 5.12$ (s, 4H, $\left.\mathrm{H}_{3}\right) ; 6.92\left(\mathrm{~s}, 2 \mathrm{H}, \mathrm{H}_{6}\right) ; 7.22\left(\mathrm{~s}, 2 \mathrm{H}, \mathrm{H}_{5}\right) ; 7.68\left(\mathrm{~s}, 2 \mathrm{H}, \mathrm{H}_{4}\right) .{ }^{13} \mathrm{C}$ NMR (50.3 MHz, DMSO$\left.d_{6}\right): \delta 36.6\left(\mathrm{C}_{3}\right) ; 68.7\left(\mathrm{C}_{1}\right) ; 75.9\left(\mathrm{C}_{2}\right) ; 119.1\left(\mathrm{C}_{5}\right) ; 129.2\left(\mathrm{C}_{6}\right) ; 137.3\left(\mathrm{C}_{4}\right)$. IR (ATR): $\tilde{v} 3218$, 3140, 3116, 2954, 2920, 1704, 1682, 1648, 1601, 1508, 1435, 1393, 1338, 1285, 1227, 1203, 1081, 1027, 945, 917, 829, 737, 656, $606 \mathrm{~cm}^{-1}$. Raman (neat powder): $\tilde{v} 2267 \mathrm{~cm}^{-1}$. HRMS (ESI+): $m / z$ calculated for $\mathrm{C}_{12} \mathrm{H}_{11} \mathrm{~N}_{4}[M+\mathrm{H}]^{+}$211.0984, found 211.0983. Anal. Calcd for $\mathrm{C}_{12} \mathrm{H}_{12} \mathrm{~N}_{4} \mathrm{O}: \mathrm{C}, 63.15 ; \mathrm{H}, 5.30 ; \mathrm{N}, 24.55$. Found: C, 62.52; H, 5.35; N, 24.01.

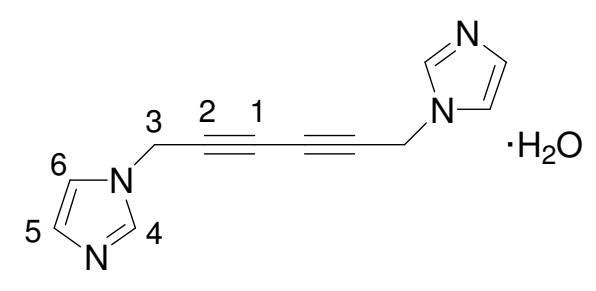

\section{Synthesis of 1,6-bis(1-benzimidazolyl)-2,4-hexadiyne monohydrate (4) and its anhydrate} (5)

$60 \mathrm{~mL}$ of a 5:1 v/v $\mathrm{CH}_{3} \mathrm{CN}-\mathrm{CH}_{2} \mathrm{Cl}_{2}$ mixture was added to a Schlenk flask containing a $1 \mathrm{~g}$ portion of $\mathbf{3}$ (2.38 $\mathrm{mmol})$, and the suspension was heated gently until complete dissolution 
was observed. Separately, a 0.844 g portion of benzimidazole ( $7.14 \mathrm{mmol}, 3$ equiv) was dissolved in $30 \mathrm{~mL} \mathrm{CH}_{3} \mathrm{CN}$ with heating, and this solution was added dropwise to the solution containing 3. The mixture was heated under reflux for $24 \mathrm{~h}$. After cooling to room temperature, the solvents were evaporated off until a small amount of an oily liquid remained. A $100 \mathrm{~mL}$ aliquot of a $1 \mathrm{M}$ aqueous $\mathrm{NaOH}$ solution was added to the crude oil and the aqueous phase was extracted with $\mathrm{CH}_{2} \mathrm{Cl}_{2}$. The organic layer was washed with a $100 \mathrm{~mL}$ portion of a $1 \mathrm{M}$ aqueous $\mathrm{NaOH}$ solution, dried over $\mathrm{MgSO}_{4}$, and the solvent was removed on a rotary evaporator. The residue was dissolved in $5 \mathrm{~mL}$ of $\mathrm{CH}_{2} \mathrm{Cl}_{2}$ and precipitated by the addition of $250 \mathrm{~mL}$ of pentane. The resulting pale brown powder was chromatographed on silica gel with use of a $94: 6 \mathrm{v} / \mathrm{v} \mathrm{CH}_{2} \mathrm{Cl}_{2}-\mathrm{CH}_{3} \mathrm{OH}$ mixture as the eluent. Slow concentration of the fractions containing the desired product to dryness afforded a cream-white solid identified as 5. $\mathrm{H}_{2} \mathrm{O}(4)(0.469 \mathrm{~g}, 60 \%) .{ }^{1} \mathrm{H}$ NMR $\left(200.1 \mathrm{MHz}, \mathrm{CDCl}_{3}\right): \delta 1.56\left(\mathrm{~s}, 2 \mathrm{H}, \mathrm{H}_{2} \mathrm{O}\right), 5.08(\mathrm{~s}, 4 \mathrm{H}$, $\left.\mathrm{H}_{3}\right), 7.30-7.39\left(\mathrm{~m}, 4 \mathrm{H}, \mathrm{H}_{6}\right.$ and $\left.\mathrm{H}_{7}\right), 7.50-7.54\left(\mathrm{~m}, 2 \mathrm{H}, \mathrm{H}_{8}\right), 7.78-7.82\left(\mathrm{~m}, 2 \mathrm{H}, \mathrm{H}_{5}\right), 7.97(\mathrm{~s}, 2 \mathrm{H}$, $\left.\mathrm{H}_{4}\right) .{ }^{13} \mathrm{C} \mathrm{NMR}\left(50.3 \mathrm{MHz}, \mathrm{CDCl}_{3}\right): \delta 35.5\left(\mathrm{C}_{3}\right), 69.6\left(\mathrm{C}_{1}\right), 72.7\left(\mathrm{C}_{2}\right), 110.0\left(\mathrm{C}_{8}\right), 120.7\left(\mathrm{C}_{5}\right)$, $122.8\left(\mathrm{C}_{6}\right), 123.6\left(\mathrm{C}_{7}\right), 133.8\left(\mathrm{C}_{10}\right), 142.5\left(\mathrm{C}_{4}\right), 144.2\left(\mathrm{C}_{9}\right) . \mathrm{IR}(\mathrm{ATR}): \tilde{v}$ 3346, 3154, 3120, 3090, 3050, 3019, 2911, 1690, 1620, 1590, 1490, 1460, 1421, 1380, 1360, 1330, 1290, 1270, 1190, 1150, 1090, 1010, 956, 944, 894, 776, 737, 660, 633, $613 \mathrm{~cm}^{-1}$. Raman (neat powder): $\tilde{v} 2266 \mathrm{~cm}^{-1}$. HRMS (ESI+): $m / z$ calculated for $\mathrm{C}_{20} \mathrm{H}_{15} \mathrm{~N}_{4}[M+\mathrm{H}]^{+} 311.1297$, found 311.1289. Anal. Calcd for $\mathrm{C}_{20} \mathrm{H}_{16} \mathrm{~N}_{4} \mathrm{O}$ : C, 73.15; H, 4.91; N, 17.06; O, 4.87. Found: C, 73.08; H, 4.94; $\mathrm{N}, 17.02 ; \mathrm{O}, 4.82$.

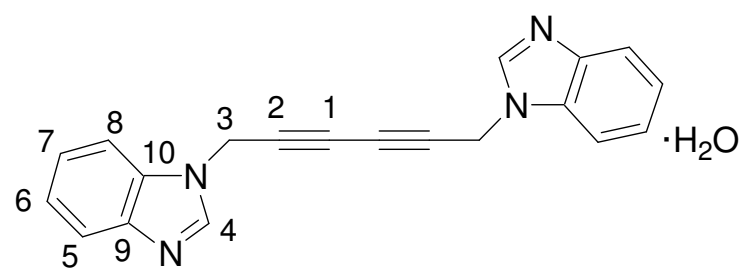

Crystallization of 4 from dichloromethane afforded light brown crystals identified as 5. Anal. Calcd for $\mathrm{C}_{20} \mathrm{H}_{14} \mathrm{~N}_{4}$ : C, 77.40; H, 4.55; N, 18.05. Found: C, 77.52; H, 4.52; N, 18.16.

\section{Stability of 2 upon dehydration}

Hydrate 2 turns into a brown solid when it is vacuum dried under a pressure of 0.1 mbar for several hours, and a brownish black powder results when it is dried with a higher vacuum $(5 \times$ $10^{-2}$ mbar). Similarly, a black powder is obtained when 2 is heated to $110{ }^{\circ} \mathrm{C}$ in air. Solidstate ${ }^{13} \mathrm{C}$ NMR spectroscopy shows that, for the brown residue, the methylene resonance of 2 at $\delta=36.9 \mathrm{ppm}$ has begun turning into a broad resonance at $\delta \approx 47 \mathrm{ppm}$, while for the black 
solids, the methylene resonance of $\mathbf{2}$ has been replaced entirely by a broad resonance centered at about $43 \mathrm{ppm}$. These observations indicate that dehydration of 2 causes neither a singlecrystal to single-crystal transformation nor amorphization, but leads instead to decomposition.

\section{Preparation of hydrated poly[1,6-bis(1-benzimidazolyl)-2,4-hexadiyne] (poly-4)}

A $100 \mathrm{mg}$ portion of monohydrate $\mathbf{4}$ was placed in a Petri dish, and the sample was irradiated in air with a UV lamp $(\lambda=254 \mathrm{~nm}$; the distance between the UV lamp and the Petri dish was $7 \mathrm{~cm})$. During the irradiation, the temperature at the surface of the sample was $30{ }^{\circ} \mathrm{C}$. The powder was irradiated for 3 days during which time it was homogenized regularly. After 3 days, a bluish gray solid was obtained which was transferred in the thimble of a Soxhlet extractor and washed for 3 days with dichloromethane to remove unreacted monomer. Poly-4 was recovered as a brownish powder with a 30\% yield. TGA measurements and infrared spectroscopy confirmed the presence of water in the polymer $(2.74 \mathrm{wt} \%)$.

\section{Structural analyses of 2 and 5}

Single crystals of 2 were grown from a $\mathrm{CH}_{2} \mathrm{Cl}_{2}$-pentane mixture (50:50 v/v). Single crystals of 5 were obtained from $\mathrm{CH}_{2} \mathrm{Cl}_{2}$. Intensity measurements were carried out at the $\mathrm{X}$-ray scattering facility of the Pôle Chimie Balard (Chemistry Department) of the Universite Montpellier II, Montpellier, France, with use of an Agilent Technologies Xcalibur-1 CCD diffractometer. The data collection temperature was $173 \mathrm{~K}$ and the crystal-to-detector distance $50 \mathrm{~mm}$. A total of 678 exposures were taken using $\omega$-scans with oscillations of $1^{\circ}$. The counting time per frame varied from 30 to $40 \mathrm{~s}$. The data were corrected for possible intensity decay and absorption using the empirical AbsPack procedure. ${ }^{104}$ Both structures were solved by ab initio charge-flipping using the SUPERFLIP ${ }^{105}$ computer program and refined by leastsquares methods on $F^{2}$ using CRYSTALS. ${ }^{106}$ Hydrogen atoms were all located in difference Fourier maps, but those attached to carbon atoms were repositioned geometrically. The hydrogen atoms were initially refined with soft restraints on bond lengths and angles $(d(\mathrm{C}-\mathrm{H})$ in the range $0.93-0.98 \AA, d(\mathrm{~N}-\mathrm{H})$ in the range $0.86-0.89 \AA, d(\mathrm{O}-\mathrm{H})=0.82 \AA$ ) and $U_{\text {iso }}(\mathrm{H})$ (in the range 1.2-1.5 times $U_{\text {eq }}$ of the parent atom) to regularize their geometry, after which the positions were refined with riding constraints. In the case of $\mathbf{2}$, as the reflection-to-parameter ratio was high, the atomic coordinates of the hydrogens were refined freely in the last cycles of refinement. Nonetheless, a restraint was placed on the H-O-H angle of the water molecule so as to prevent large deviations from $108^{\circ}$ upon refinement. Final $R$ values and relevant 
crystallographic data are given in Table $1{ }^{69}$ All of the structural drawings were prepared with use of the three-dimensional graphical visualization program OLEX2. ${ }^{107}$

\section{Structural analysis of 4}

The powder X-ray diffraction diagram of $\mathbf{4}$ was recorded on a PANAlytical Xpert-PRO diffractometer equipped with an $\mathrm{X}$ 'celerator detector using $\mathrm{Ni}$-filtered $\mathrm{Cu} \mathrm{K} \alpha$ radiation. The diffractogram was rebinned to a step-size of $\Delta 2 \theta=0.017^{\circ}$. A peak search was performed with use of the WinPLOTR software, ${ }^{108}$ and indexing was performed with the DICVOL04 program. ${ }^{109}$ A dozen of different monoclinic solutions were found with M20 indices between 10 and 17 and reasonable cell volumes. An estimate of the cell volume was obtained by multiplying the number of non-hydrogen atoms of each monomer, 24 , by 18 , the approximate volume occupied by a non-hydrogen atom in a typical organic compound. To get the theoretical cell volume, this value was further multiplied by the multiplicity of the general Wyckoff site of a typical monoclinic space group, 4 for a centrosymmetric space group and 2 for a non-centrosymmetric one. For a centrosymmetric space group, a value of $1728 \AA^{3}$ was obtained. Instead of ranking the solutions according to their closeness to the theoretical volume, a Le Bail fit was carried out for each of the possible monoclinic solutions with volumes in the range 1600-1900 $\AA^{3}$. The cell with parameters $a=19.9913, b=19.7499, c=$ $4.4964 \AA, \beta=97.193^{\circ}, \mathrm{V}=1761.31 \AA^{3}$ was found to give the best fit, other solutions missing at least one observed peak over the entire $2 \theta$ range. Rather than using this cell for structure solution and refinement, the Niggli-reduced cell was used and Le Bail refined, giving the following cell parameters: $a=4.5067(5), b=19.789(2), c=19.972(2) \AA, \beta=95.742(7)^{\circ}$. Determination of the space group was done with the FOX program ${ }^{110}$ that ranks each possible space group according to its Le Bail fit. The non-centrosymmetric space group $P 2_{1}$ and the centrosymmetric one $P 2_{1} / m$ proved to be the best candidates, centrosymmetric space groups such as $P 2_{1} / a, P 2_{1} / c$, and $P 2_{1} / n$ giving worse Le Bail fits, mainly because of the clear presence of reflections forbidden by symmetry in the latter three space groups. The final agreement factors for the Le Bail fit in $P 2_{1}$ and $P 2_{1} / m$ were: $R_{\mathrm{wp}}=6.939, R_{\mathrm{p}}=5.367$, and $R_{\exp }$ $=3.650 \%$.

For structure solution, space group $P 2_{1}$ was preferred to $P 2_{1} / m$ because of its much higher frequency of appearance in the Cambridge Structural Database. The choice of the noncentrosymmetric space group implies the presence of exactly two independent diacetylene molecules in the asymmetric part of the unit cell. It is worth mentioning that the accepted 
solution presented a rather high volume per non-hydrogen atom, $18.45 \AA^{3}$, as compared with that of its pseudopolymorph $\mathbf{5}, 16.04 \AA^{3}$ (not corrected for thermal expansion effects). This could imply the presence of water molecules in the structure of 4 . Indeed, the presence of two water molecules would bring the volume per non-hydrogen atom to $16.40 \AA^{3}$, close to that of 5. Yet, it is noteworthy that the volume per non-hydrogen atom is also influenced by the packing of the molecules, the presence of $\pi-\pi$ interactions giving rise in general to compact structures. So, if the structure of $\mathbf{4}$ were to exhibit weaker $\pi-\pi$ interactions than that of $\mathbf{5}$, the volume per non-hydrogen atom would come close to the observed value and the presence of water molecules would not be required.

Two independent rigid body representations of the diacetylene molecule with geometries imported from the structure of $\mathbf{5}$ (without hydrogen atoms) were used as an initial model for a simulated annealing structure solution attempt using Topas-A. ${ }^{111}$ Besides the three Eulerian orientation angles and five position vector components (the y-position of one of the rigid bodies was set at 0.00 so as to fix the origin in the polar space group $P 2_{1}$ ), four torsion angles were optimized corresponding to the rotations of the benzimidazole rings about the $\mathrm{C} \equiv \mathrm{C}-\mathrm{C} \equiv \mathrm{C}$ fragments. Furthermore, it was necessary to use anti-bump restraints between individual molecules (set at $3.0 \AA$ ) so that chemically reasonable solutions could be obtained. Different solutions were found, all with $R_{\mathrm{wp}}$ values around 27-30\%. Only one solution proved to be reasonable in terms of packing interactions and possible polymerization reactivity.

This solution was further refined with one global $B_{\text {iso }}$ parameter for the two independent molecules, with all hydrogen $B$ factors set at 1.2 times the global $B$ factor. By using a slow step-by-step refinement, anti-bump restraints turned out to be no longer necessary. The resulting structure was found to contain voids amounting to a total of $175 \AA^{3}$ per unit cell, this volume being sufficiently large to accommodate water molecules. A difference Fourier map was generated by use of the CRYSTALS software package that revealed the presence of two oxygen positions in close proximity to nitrogen atoms, the oxygen-nitrogen distance being suggestive of a hydrogen bond between these atoms. The oxygen positions were introduced one at a time in the structure refinement, with use of rigid bodies to represent the water molecules and restraints to place and orient these molecules correctly with respect to the nitrogen atoms. One global isotropic atomic displacement parameter was used for the two water molecules which refined to a rather high value, suggesting a slight underoccupancy of the two sites that could be due to partial desolvation. However, the data are not of sufficiently high quality for this hypothesis to be ascertained. 
The final agreement factors for the Rietveld refinement are: $R_{\mathrm{wp}}=6.921, R_{\mathrm{p}}=5.253$, and $R_{\exp }$ $=3.524 \%$, in excellent agreement with the final Le Bail (not model-based) results. The Rietveld fitting results are shown in Figure S7 of the Supplementary Material. 


\section{Acknowledgements}

We warmly thank Ms. Dominique Granier from the Institut Charles Gerhardt Montpellier (UMR 5253 CNRS-UM2-ENSCM-UM1, Université Montpellier II, Montpellier, France) for carrying out the single-crystal and powder X-ray diffraction analyses described herein. We are also grateful to Ms. Nathalie Masquelez from the Institut Européen des Membranes (CNRS UMR 5635, Université Montpellier II, Montpellier, France) for her help with the coupled TGA-DSC experiments. 


\section{References}

1. G. Wegner, Z. Naturforsch. B, 1969, 24, 824-832.

2. $\quad$ R. H. Baughman, J. Polym. Sci., Polym. Phys. Ed., 1974, 12, 1511-1535.

3. G. Wegner, Pure Appl. Chem., 1977, 49, 443-454.

4. $\quad$ V. Enkelmann, Adv. Polym. Sci., 1984, 63, 91-136.

5. G. Wegner, Makromol. Chem., 1971, 145, 85-94.

6. K. C. Yee and R. R. Chance, J. Polym. Sci., Polym. Phys. Ed., 1978, 16, 431-441.

7. V. Enkelmann, Acta Crystallogr., Sect. B, 1977, 33, 2842-2846.

8. V. Enkelmann, R. J. Leyrer, G. Schleier and G. Wegner, J. Mater. Sci., 1980, 15, 168176.

9. V. Enkelmann and G. Schleier, Acta Crystallogr., Sect. B, 1980, 36, 1954-1956.

10. F. Dubin, R. Melet, T. Barisien, R. Grousson, L. Legrand, M. Schott and V. Voliotis, Nat. Phys., 2006, 2, 32-35.

11. F. L. Hirshfield and G. M. J. Schmidt, J. Polym. Sci., Part A, 1964, 2, 2181-2190.

12. R. R. Chance and G. N. Patel, J. Polym. Sci., Polym. Phys. Ed., 1978, 16, 859-881.

13. H. Sixl, Adv. Polym. Sci., 1984, 63, 49-90.

14. W. D. Huntsman, in The chemistry of functional groups, supplement $C$ : the chemistry of triple-bonded functional groups Part 2, ed. S. Patai and Z. Rappoport, Wiley, Chichester, U.K., 1983, Chapter 22, pp 917-980.

15. R. H. Baughman, J. Appl. Phys., 1972, 43, 4362-4370.

16. H. Matsuda, H. Nakanishi, T. Hosomi and M. Kato, Macromolecules, 1988, 21, 12381240.

17. V. Enkelmann and G. Wegner, Angew. Chem., 1977, 89, 432.

18. V. Enkelmann, R. J. Leyrer and G. Wegner, Makromol. Chem., 1979, 180, 1787-1795.

19. G. N. Patel, E. N. Duesler, D. Y. Curtin and I. C. Paul, J. Am. Chem. Soc., 1980, 102, 461-466.

20. H. Tachibana, R. Kumai, N. Hosaka and Y. Tokura, Chem. Mater., 2001, 13, 155-158.

21. S. Spagnoli, M. Schott, M. Johnson and L. Toupet, Chem. Phys., 2007, 333, 236-245.

22. M. Masuda, T. Hanada, K. Yase and T. Shimizu, Macromolecules, 1998, 31, 94039405.

23. M. Masuda, T. Hanada, Y. Okada, K. Yase and T. Shimizu, Macromolecules, 2000, 33, 9233-9238.

24. O. J. Dautel, M. Robitzer, J.-P. Lère-Porte, F. Serein-Spirau and J. J. E. Moreau, J. Am. Chem. Soc., 2006, 128, 16213-16223.

25. J. L. Foley, L. Li, D. J. Sandman, M. J. Vela, B. M. Foxman, R. Albro and C. J. Eckhardt, J. Am. Chem. Soc., 1999, 121, 7262-7263.

26. J. Kaiser, G. Wegner and E. W. Fischer, Isr. J. Chem., 1972, 10, 157-171.

27. J. J. Kane, R.-F. Liao, J. W. Lauher and F. W. Fowler, J. Am. Chem. Soc., 1995, 117, 12003-12004.

28. T. L. Nguyen, F. W. Fowler and J. W. Lauher, Mol. Cryst. Liq. Cryst. Sci. Technol., Sect. A, 1998, 313, 253-258.

29. F. W. Fowler and J. W. Lauher, J. Phys. Org. Chem., 2000, 13, 850-857.

30. X. Ouyang, F. W. Fowler and J. W. Lauher, J. Am. Chem. Soc., 2003, 125, 1240012401.

31. S. M. Curtis, N. Le, T. Nguyen, X. Ouyang, T. Tran, F. W. Fowler and J. W. Lauher, Supramol. Chem., 2005, 17, 31-36.

32. S. M. Curtis, N. Le, F. W. Fowler and J. W. Lauher, Cryst. Growth Des., 2005, 5, 2313-2321. 
33. J. W. Lauher, F. W. Fowler and N. S. Goroff, Acc. Chem. Res., 2008, 41, 1215-1229.

34. Z. Li, F. W. Fowler and J. W. Lauher, J. Am. Chem. Soc., 2009, 131, 634-643.

35. N. S. Goroff, S. M. Curtis, J. A. Webb, F. W. Fowler and J. W. Lauher, Org. Lett., 2005, 7, 1891-1893.

36. A. Sun, J. W. Lauher and N. S. Goroff, Science (Washington, DC, U. S.), 2006, 312, 1030-1034.

37. C. Wilhelm, S. A. Boyd, S. Chawda, F. W. Fowler, N. S. Goroff, G. P. Halada, C. P. Grey, J. W. Lauher, L. Luo, C. D. Martin, J. B. Parise, C. Tarabrella and J. A. Webb, J. Am. Chem. Soc., 2008, 130, 4415-4420.

38. L. Luo, C. Wilhelm, A. Sun, C. P. Grey, J. W. Lauher and N. S. Goroff, J. Am. Chem. Soc., 2008, 130, 7702-7709.

39. L. Luo, C. Wilhelm, C. N. Young, C. P. Grey, G. P. Halada, K. Xiao, I. N. Ivanov, J. Y. Howe, D. B. Geohegan and N. S. Goroff, Macromolecules, 2011, 44, 2626-2631.

40. G. W. Coates, A. R. Dunn, L. M. Henling, D. A. Dougherty and R. H. Grubbs, Angew. Chem., Int. Ed. Engl., 1997, 36, 248-251.

41. R. Xu, V. Gramlich and H. Frauenrath, J. Am. Chem. Soc., 2006, 128, 5541-5547.

42. R. Xu, W. B. Schweizer and H. Frauenrath, J. Am. Chem. Soc., 2008, 130, 1143711445.

43. M. P. Martin-Redondo, L. Scoles, B. T. Sterenberg, K. A. Udachin and A. J. Carty, J. Am. Chem. Soc., 2005, 127, 5038-5039.

44. F. Toda, Top. Curr. Chem., 1987, 140, 43-69.

45. F. Toda, Top. Curr. Chem., 1988, 149, 211-238.

46. F. Toda, in Solid-state Supramolecular Chemistry: Crystal Engineering; Comprehensive Supramolecular Chemistry, Vol. 6, ed. D. D. MacNicol, F. Toda and R. Bishop, Elsevier, Oxford, U.K., 1996, Chapter 15, pp 465-516.

47. F. Toda and K. Akagi, Tetrahedron Lett., 1968, 3695-3698.

48. F. Toda, D. L. Ward and H. Hart, Tetrahedron Lett., 1981, 22, 3865-3868.

49. H. Hart, L.-T. W. Lin and D. L. Ward, J. Am. Chem. Soc., 1984, 106, 4043-4045.

50. C. Brouty, P. Spinat and A. Whuler, Acta Crystallogr., Sect. B, 1980, 36, 2624-2628.

51. F. Carré, S. G. Dutremez, C. Guérin, B. J. L. Henner, A. Jolivet, V. Tomberli and F. Dahan, Organometallics, 1999, 18, 770-781.

52. E. Hädicke, E. C. Mez, C. H. Krauch, G. Wegner and J. Kaiser, Angew. Chem., 1971, 83, 253-254.

53. B. Tieke, Makromol. Chem., 1984, 185, 1455-1467.

54. A. Sarkar, S. Okada, H. Nakanishi and H. Matsuda, Macromolecules, 1998, 31, 91749180.

55. A. Sarkar and S. S. Talwar, J. Chem. Soc., Perkin Trans. 1, 1998, 4141-4146.

56. A. Sarkar, S. Okada, H. Matsuzawa, H. Matsuda and H. Nakanishi, J. Mater. Chem., 2000, 10, 819-828.

57. $\mathrm{p} K_{\mathrm{b}}$ of the imine nitrogen of 1-methylimidazole $=6.88 ; \mathrm{p} K_{\mathrm{b}}$ of the imine nitrogen of $1-$ methylbenzimidazole $=8.45 ; \mathrm{p} K_{\mathrm{b}}$ of pyridine $=8.77 ; \mathrm{p} K_{\mathrm{b}}$ of quinoline $=9.10 ; \mathrm{p} K_{\mathrm{b}}$ of pyrimidine $=12.77$. See: (a) J. Catalan, J. L. M. Abboud and J. Elguero, $A d v$. Heterocycl. Chem. 1987, 41, 187-274; (b) CRC Handbook of Chemistry and Physics, ed. D. R. Lide, CRC Press, Boca Raton, FL, 84th edn, 2003.

58. K. Bouchmella, B. Boury, S. G. Dutremez and A. van der Lee, Chem. Eur. J., 2007, 13, 6130-6138.

59. (a) A. S. Hay, J. Org. Chem. 1962, 27, 3320-3321; (b) D. R. M. Walton and F. Waugh, J. Organomet. Chem. 1972, 37, 45-56; (c) R. Eastmond, T. R. Johnson and D. R. M. Walton, Tetrahedron 1972, 28, 4601-4616; (d) B. N. Ghose, Synth. React. Inorg. Met.-Org. Chem. 1994, 24, 29-52; (e) L. Brandsma, Studies in Organic 
Chemistry 34: Preparative Acetylenic Chemistry, Elsevier, Amsterdam, 2nd edn, $1988, \mathrm{p} 219$.

60. J.-P. Collin, J. Frey, V. Heitz, J.-P. Sauvage, C. Tock and L. Allouche, J. Am. Chem. Soc., 2009, 131, 5609-5620.

61. J. M. Njus and D. J. Sandman, Solid State Nucl. Magn. Reson., 2006, 29, 251-257.

62. I. H. Jenkins, A. K. Kar, W. E. Lindsell, C. Murray, P. N. Preston, C. Wang and B. S. Wherrett, Macromolecules, 1996, 29, 6365-6370.

63. P. V. Tkachenko, I. I. Popov and A. M. Simonov, Khim. Geterotsikl. Soedin., 1974, 1540-1543.

64. I. I. Popov, P. V. Tkachenko and A. M. Simonov, Khim. Geterotsikl. Soedin., 1973, 551-552.

65. S. M. Tret'yak, V. V. Mitkevich and L. F. Sukhodub, Kristallografiya, 1987, 32, 12681271.

66. C. Sun, D. Zhou, D. J. W. Grant and V. G. Young, Jr., Acta Crystallogr., Sect. E: Struct. Rep. Online, 2002, E58, o368-o370.

67. L. Deng, W. Wang and J. Lv, Acta Crystallogr., Sect. E: Struct. Rep. Online, 2007, E63, o4204, So4204/1-So4204/10.

68. G. Koyama, H. Nakamura, H. Umezawa and Y. Iitaka, Acta Crystallogr., Sect. B, 1976, 32, 969-972.

69. CCDC-892822 (5), CCDC-892823 (2), and CCDC-892824 (4) contain the supplementary crystallographic data for this paper. These data can be obtained free of charge from the Cambridge Crystallographic Data Centre via www.ccdc.cam.ac.uk/data request/cif.

70. C. Janiak, J. Chem. Soc., Dalton Trans., 2000, 3885-3896.

71. L. Hu, E. C. Spencer, G. Wang, G. Yee, C. Slebodnick and B. E. Hanson, Inorg. Chem. Commun., 2008, 11, 982-984.

72. S. Zhang, S. Yang, J. Lan, Y. Tang, Y. Xue and J. You, J. Am. Chem. Soc., 2009, 131, 1689-1691.

73. C.-Y. Chen, P.-Y. Cheng, H.-H. Wu and H. M. Lee, Inorg. Chem., 2007, 46, 56915699.

74. Y.-Y. Liu, J.-F. Ma, J. Yang, J.-C. Ma and G.-J. Ping, CrystEngComm, 2008, 10, 565572.

75. G.-C. Xu, Q. Hua, T.-a. Okamura, Z.-S. Bai, Y.-J. Ding, Y.-Q. Huang, G.-X. Liu, W.Y. Sun and N. Ueyama, CrystEngComm, 2009, 11, 261-270.

76. W.-Y. Sun, J. Fan, J. Hu, K.-B. Yu and W.-X. Tang, J. Chem. Crystallogr., 2000, 30, 115-118.

77. (a) F. H. Allen, Acta Crystallogr., Sect. B, 2002, 58, 380-388; (b) CSD Version 5.32, November 2010, plus May 2011 update (562,000 entries in total), Cambridge Crystallographic Data Centre, 12 Union Road, Cambridge, CB2 1EZ, U.K.

78. H.-J. Knölker and R. Boese, J. Chem. Soc., Perkin Trans. 1, 1990, 1821-1822.

79. H.-J. Knölker, R. Boese, D. Döring, A.-A. El-Ahl, R. Hitzemann and P. G. Jones, Chem. Ber., 1992, 125, 1939-1951.

80. M. Królikowska and J. Garbarczyk, Z. Kristallogr. - New Cryst. Struct., 2005, 220, 103-104.

81. W. White, Z. M. Hudson, X. Feng, S. Han, Z.-H. Lu and S. Wang, Dalton Trans., 2010, 39, 892-899.

82. Z.-X. Li, Y. Zuo and T.-L. Hu, Acta Crystallogr., Sect E: Struct. Rep. Online, 2008, E64, o141.

83. M. Akkurt, S. Karaca, H. Küçükbay and O. Büyükgüngör, Acta Crystallogr., Sect. E: Struct. Rep. Online, 2007, E63, o1065-o1066. 
84. (a) F. H. Allen, Acta Crystallogr., Sect. B, 2002, 58, 380-388; (b) CSD Version 5.33, November 2011, plus November 2011 update (586,977 entries in total), Cambridge Crystallographic Data Centre, 12 Union Road, Cambridge, CB2 1EZ, U.K.

85. P. Ball, Chem. Rev., 2008, 108, 74-108.

86. D. Zhong, S. K. Pal and A. H. Zewail, Chem. Phys. Lett., 2011, 503, 1-11.

87. Single-crystal to single-crystal transformations by removal of water molecules have been reported for several coordination compounds. See: (a) D. Sarma and S. Natarajan, Cryst. Growth Des., 2011, 11, 5415-5423; (b) R. Haldar and T. K. Maji, CrystEngComm, 2012, 14, 684-690.

88. J. P. Paraknowitsch, J. Zhang, D. Su, A. Thomas and M. Antonietti, Adv. Mater., 2010, 22, 87-92.

89. M. C. Suh and S. C. Shim, Chem. Mater., 1997, 9, 192-200.

90. L. Zhao, N. Baccile, S. Gross, Y. Zhang, W. Wei, Y. Sun, M. Antonietti and M.-M. Titirici, Carbon, 2010, 48, 3778-3787.

91. F. Carré, N. Devylder, S. G. Dutremez, C. Guérin, B. J. L. Henner, A. Jolivet, V. Tomberli and F. Dahan, Organometallics, 2003, 22, 2014-2033.

92. S. G. Dutremez, unpublished results.

93. K. Fahsi, S. G. Dutremez, A. Vioux and L. Viau, J. Mat. Chem. A, 2013, DOI: 10.1039/C3TA01154B.

94. M. Laskoski, W. Steffen, J. G. M. Morton, M. D. Smith and U. H. F. Bunz, J. Am. Chem. Soc., 2002, 124, 13814-13818.

95. D.-C. Lee, S. K. Sahoo, A. L. Cholli and D. J. Sandman, Macromolecules, 2002, 35, 4347-4355.

96. M. Schott, J. Phys. Chem. B, 2006, 110, 15864-15868.

97. G. Wegner, J. Polym. Sci., Part B, 1971, 9, 133-144.

98. B. Sadek, Pharma Chem., 2011, 3, 410-419.

99. C. B. Aakeröy, S. Forbes and J. Desper, CrystEngComm, 2012, 14, 2435-2443.

100. J. Ohkanda, C. L. Strickland, M. A. Blaskovich, D. Carrico, J. W. Lockman, A. Vogt, C. J. Bucher, J. Sun, Y. Qian, D. Knowles, E. E. Pusateri, S. M. Sebti and A. D. Hamilton, Org. Biomol. Chem., 2006, 4, 482-492.

101. T. L. Nguyen, F. W. Fowler and J. W. Lauher, J. Am. Chem. Soc., 2001, 123, $11057-$ 11064.

102. D. E. Bierer, J. M. Dener, L. G. Dubenko, R. E. Gerber, J. Litvak, S. Peterli, P. PeterliRoth, T. V. Truong, G. Mao and B. E. Bauer, J. Med. Chem., 1995, 38, 2628-2648.

103. L. Rougeau, D. Picq, M. Rastello and Y. Frantz, Tetrahedron, 2008, 64, 9430-9436.

104. CrysAlis ${ }^{\text {Pro }}$, Oxford Diffraction Ltd., 2006.

105. L. Palatinus and G. Chapuis, J. Appl. Crystallogr., 2007, 40, 786-790.

106. P. W. Betteridge, J. R. Carruthers, R. I. Cooper, K. Prout and D. J. Watkin, J. Appl. Crystallogr., 2003, 36, 1487.

107. O. V. Dolomanov, L. J. Bourhis, R. J. Gildea, J. A. K. Howard and H. Puschmann, J. Appl. Crystallogr., 2009, 42, 339-341.

108. T. Roisnel and J. Rodríguez-Carvajal, Mater. Sci. Forum, 2001, 378-381, 118-123.

109. A. Boultif and D. Louër, J. Appl. Crystallogr., 2004, 37, 724-731.

110. V. Favre-Nicolin and R. Černý, J. Appl. Crystallogr., 2002, 35, 734-743.

111. A. Coelho, Topas-A: General Profile and Structure Analysis Software for Powder Diffraction Data, 2005, http://www.topas-academic.net/. 


\section{Legends}

Scheme 1. Schematic representation of the topochemical principle for diacetylene polymerization.

Scheme 2. Syntheses of compounds 1, 2, 4, and 5 .

Scheme 3. Generic numbering scheme for imidazolyl carbons.

Figure 1. View along the $a$ axis showing the organization of $\mathbf{2}$ in the crystalline state.

Figure 2. Hydrogen-bonding interactions involving the water molecule in 2.

Figure 3. View of the organic shell making up the cavity around the water molecule in $\mathbf{2}$.

Figure 4. Topological representation of the 1D chains in $\mathbf{2}$ viewed down the crystallographic $b$ axis.

Figure 5. View showing the $\pi \cdots \pi$ interactions between benzimidazolyl groups in a polymeric chain of 5 .

Figure 6. View along the $b$ axis showing the two kinds of polymeric chains, shown in blue and green, present in crystalline $\mathbf{5}$.

Figure 7. Close-up view showing the acac-like hydrogen-bonding pattern and the $\mathrm{C}-\mathrm{H} \cdots \pi$ interaction between two "blue" chains in $\mathbf{5}$.

Figure 8. Close-up view showing the $\mathrm{C}-\mathrm{H} \cdots \pi$ interaction between one "blue" chain and one "green" chain in $\mathbf{5}$.

Figure 9. Schematic representation of the build-up of a polydiacetylene thread from molecules located in "blue" and "green" chains (red dashed lines). 
Figure 10. View along the $a$ axis showing the organization of 4 in the crystalline state.

Figure 11. Close-up view showing one water ribbon and the interactions of this ribbon with neighboring benzimidazolyl groups in crystalline 4 .

Figure 12. Close-up view showing one $\pi \cdots \pi$ interaction in solid 4 .

Figure 13. XRD patterns of 2 (a), 2 evacuated under a vacuum of $5 \times 10^{-2}$ mbar (b), and 2 heated to $110{ }^{\circ} \mathrm{C}$ in air (c). The asterisk denotes an artifact.

Figure 14. Infrared spectra of 2 (a), 2 evacuated under a vacuum of 0.1 mbar (b), 2 evacuated under a vacuum of $5 \times 10^{-2} \mathrm{mbar}(\mathrm{c})$, and 2 heated to $110^{\circ} \mathrm{C}$ in air (d).

Figure 15. CP/MAS ${ }^{13} \mathrm{C}$ NMR spectra of 2 (a), 2 evacuated under a vacuum of 0.1 mbar (b), 2 evacuated under a vacuum of $5 \times 10^{-2} \mathrm{mbar}(\mathrm{c})$, and 2 heated to $110^{\circ} \mathrm{C}$ in air (d).

Figure 16. CP/MAS ${ }^{13} \mathrm{C}$ NMR spectra of 4 and poly-4.

Figure 17. XRD patterns of 4 (a), unwashed poly-4 (b), and washed poly-4 (c). 
Table 1. Crystal data and experimental details of data collection and refinement for compounds $\mathbf{2}$ and $\mathbf{5}$.

\begin{tabular}{|c|c|c|}
\hline empirical formula & $\mathrm{C}_{12} \mathrm{H}_{12} \mathrm{~N}_{4} \mathrm{O}$ & $\mathrm{C}_{20} \mathrm{H}_{14} \mathrm{~N}_{4}$ \\
\hline fw & 228.26 & 310.35 \\
\hline cryst color and habit & transparent prism & transparent prism \\
\hline cryst size $\left(\mathrm{mm}^{3}\right)$ & $0.45 \times 0.35 \times 0.25$ & $0.30 \times 0.25 \times 0.15$ \\
\hline cryst syst & orthorhombic & monoclinic \\
\hline space group & Pbcn (No. 60) & $P 2_{1} / c($ No. 14$)$ \\
\hline$a(\AA)$ & $10.3530(3)$ & $11.3990(4)$ \\
\hline$b(\AA)$ & $12.3146(3)$ & $15.5354(5)$ \\
\hline$c(\AA)$ & $9.4233(2)$ & $9.2351(3)$ \\
\hline$\alpha(\mathrm{deg})$ & 90 & 90 \\
\hline$\beta(\operatorname{deg})$ & 90 & $109.568(4)$ \\
\hline$\gamma(\mathrm{deg})$ & 90 & 90 \\
\hline$V\left(\AA^{3}\right)$ & $1201.41(5)$ & $1540.97(10)$ \\
\hline$Z$ & 4 & 4 \\
\hline$T(\mathrm{~K})$ & 173 & 173 \\
\hline$\rho_{\text {calcd }}\left(\mathrm{g} \mathrm{cm}^{-3}\right)$ & 1.262 & 1.338 \\
\hline$F(000)$ & 480 & 648 \\
\hline$\mu\left(\mathrm{mm}^{-1}\right)$ & 0.085 & 0.082 \\
\hline$T_{\min }, T_{\max }$ & $0.89516,1.00000$ & $0.96207,1.00000$ \\
\hline graphite-monochromated & 0.71073 & 0.71073 \\
\hline \multicolumn{3}{|l|}{$\operatorname{Mo}_{\mathrm{K} \alpha}$ radiation $(\AA)$} \\
\hline$\theta$ range $(\mathrm{deg})$ & $3.309-29.162$ & $2.797-26.526$ \\
\hline \multirow[t]{3}{*}{ index ranges } & $-13 \leq h \leq 14$ & $-14 \leq h \leq 14$ \\
\hline & $-16 \leq k \leq 16$ & $-18 \leq k \leq 19$ \\
\hline & $-12 \leq l \leq 12$ & $-11 \leq l \leq 11$ \\
\hline data collected & 24150 & 23653 \\
\hline unique data, $R_{\text {int }}$ & $1546,0.032$ & $2940,0.050$ \\
\hline obsd data $(I>2 \sigma(I))$ & 1262 & 2065 \\
\hline L.S. params, restraints & 96,1 & 217,0 \\
\hline
\end{tabular}




$\begin{array}{lll}R,{ }^{a} R_{\mathrm{w}}{ }^{b} \text { (obsd reflns) } & 0.0395,0.0947 & 0.0440,0.0885 \\ R^{a}{ }^{a} R_{\mathrm{w}}{ }^{b} \text { (all reflns) } & 0.0540,0.1093 & 0.0802,0.1142 \\ \text { weighting scheme }^{c} & 462,756,465,192,40.6 & 162,256,157,64.9,15.2 \\ \text { max shift/esd } & 0.0002088 & 0.0002795 \\ \text { GOF }\left(F^{2}\right) & 0.9727 & 0.9700 \\ \Delta \rho_{\min }, \Delta \rho_{\max }\left(\mathrm{e} \AA^{-3}\right) & -0.29,0.28 & -0.50,0.45\end{array}$

${ }^{a} R=\Sigma\left\|F_{\mathrm{o}}|-| F_{\mathrm{c}}\right\| / \Sigma\left|F_{\mathrm{o}}\right| \cdot{ }^{b} R_{\mathrm{w}}=\left[\Sigma\left(\mathrm{w}\left(F_{\mathrm{o}}{ }^{2}-F_{\mathrm{c}}{ }^{2}\right)^{2}\right) / \Sigma\left(\mathrm{w}\left(F_{\mathrm{o}}{ }^{2}\right)^{2}\right)\right]^{1 / 2} \cdot{ }^{c} w=[$ weight $][1-$ $\left.(\Delta F / 6 \sigma(F))^{2}\right]^{2} ;$ [weight $]=1.0 /\left[A_{0} T_{0}(\mathrm{x})+A_{1} T_{1}(\mathrm{x})+\ldots+A_{\mathrm{n}-1} T_{\mathrm{n}-1}(\mathrm{x})\right]$ where $A_{\mathrm{i}}$ are the Chebychev coefficients listed in the Table and $\mathrm{x}=F_{\text {calcd }} / F_{\max }$. 
Table 2. Geometrical parameters for the hydrogen-bonding interactions involving the water molecule in solvate 2 .

\begin{tabular}{|c|c|c|c|c|}
\hline \multirow[b]{2}{*}{ interaction $^{a}$} & \multicolumn{3}{|c|}{ distance/ $/ ̊$} & \multirow{2}{*}{$\begin{array}{l}\text { angle/deg } \\
\text { D-H } \cdots A\end{array}$} \\
\hline & D-H & $\mathrm{H} \cdots \mathrm{A}$ & $\mathrm{D} \cdots \mathrm{A}$ & \\
\hline $\mathrm{O} 1-\mathrm{H} 11^{\mathrm{i}} \cdots \mathrm{N} 4^{\mathrm{iv}}$ & 0.869 & 1.986 & 2.853 & 175.69 \\
\hline $\mathrm{O} 1-\mathrm{H} 11 \cdots \mathrm{N} 4^{\mathrm{v}}$ & 0.869 & 1.986 & 2.853 & 175.69 \\
\hline $\mathrm{C} 3^{\mathrm{ii}}-\mathrm{H} 31^{\mathrm{ii}} \cdots \mathrm{O} 1$ & 0.984 & 2.756 & 3.559 & 139.20 \\
\hline $\mathrm{C} 3^{\mathrm{iii}}-\mathrm{H} 31^{\mathrm{iii}} \cdots \mathrm{O} 1$ & 0.984 & 2.756 & 3.559 & 139.20 \\
\hline C6-H61… 1 & 0.972 & 2.509 & 3.341 & 143.53 \\
\hline $\mathrm{C} 6^{\mathrm{i}}-\mathrm{H} 61^{\mathrm{i}} \cdots \mathrm{O} 1$ & 0.972 & 2.509 & 3.341 & 143.53 \\
\hline $\mathrm{C} 7^{\mathrm{ii}}-\mathrm{H} 72^{\mathrm{ii}} \ldots \mathrm{O} 1$ & 0.998 & 2.478 & 3.426 & 158.53 \\
\hline $\mathrm{C}^{\mathrm{iii}}-\mathrm{H}_{72} 2^{\mathrm{iii}} \cdots \mathrm{O} 1$ & 0.998 & 2.478 & 3.426 & 158.53 \\
\hline
\end{tabular}

${ }^{a}$ Symmetry codes: (i) $2-x, y, 3 / 2-z$; (ii) $1 / 2+x, 1 / 2-y, 1-z$; (iii) $3 / 2-x, 1 / 2-y, 1 / 2+z$; (iv) $1 / 2+x,-1 / 2+y, 3 / 2-z$; (v) $3 / 2-x,-1 / 2+y, z$. 
Table 3. Geometrical parameters for the $\mathrm{C}-\mathrm{H} \cdots \pi$ interactions present in solvate 2 .

\begin{tabular}{|c|c|c|c|c|}
\hline \multirow[b]{2}{*}{ interaction $^{a, b}$} & \multicolumn{3}{|c|}{ distance $/ \AA$} & \multirow{2}{*}{$\begin{array}{c}\text { angle/deg } \\
\mathrm{C}-\mathrm{H} \cdots \mathrm{C} / \mathrm{Cg}\end{array}$} \\
\hline & $\mathrm{C}-\mathrm{H}$ & $\mathrm{H} \cdots \mathrm{C} / \mathrm{Cg}$ & $\mathrm{C} \cdots \mathrm{C} / \mathrm{Cg}$ & \\
\hline $\mathrm{C} 5-\mathrm{H} 51 \cdots \mathrm{C} 5^{\mathrm{i}}$ & 0.999 & 3.458 & 3.983 & 114.87 \\
\hline C5-H51 $\cdots \mathrm{C}^{\mathrm{i}}$ & 0.999 & 3.553 & 3.962 & 106.95 \\
\hline $\mathrm{C} 5-\mathrm{H} 51 \cdots \mathrm{Cg}(\mathrm{d})^{\mathrm{i}}$ & 0.999 & 3.440 & 3.914 & 111.22 \\
\hline $\mathrm{C} 5-\mathrm{H} 51 \cdots \mathrm{C} 8^{\mathrm{ii}}$ & 0.999 & 2.944 & 3.719 & 135.05 \\
\hline $\mathrm{C} 5-\mathrm{H} 51 \cdots \mathrm{C} 9^{\mathrm{ii}}$ & 0.999 & 3.003 & 3.759 & 133.28 \\
\hline $\mathrm{C} 5-\mathrm{H} 51 \cdots \mathrm{Cg}(\mathrm{t})^{\mathrm{ii}}$ & 0.999 & 2.913 & 3.691 & 135.32 \\
\hline $\mathrm{C} 6-\mathrm{H} 61 \cdots \mathrm{C}^{\mathrm{i}}$ & 0.972 & 3.481 & 3.962 & 112.90 \\
\hline 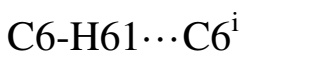 & 0.972 & 3.034 & 3.694 & 126.28 \\
\hline C6-H61 ‥ Cg(d) ${ }^{\mathrm{i}}$ & 0.972 & 3.194 & 3.769 & 119.55 \\
\hline
\end{tabular}


Table 4. Geometrical parameters for the $\pi \cdots \pi$ interactions present in solvate 4 .

\begin{tabular}{|c|c|c|c|c|}
\hline interaction $^{a, b}$ & $\mathrm{Cg}-\mathrm{Cg} / \AA^{c}$ & beta/ ${ }^{o d}$ & CgI_Perp/ $\AA^{e}$ & slippage $/ \AA^{f}$ \\
\hline $\mathrm{Cg}(1) \cdots \mathrm{Cg}(2)$ & 3.4035 & 18.59 & 3.2259 & 1.085 \\
\hline $\mathrm{Cg}(3) \cdots \mathrm{Cg}(4)$ & 3.3676 & 23.61 & 3.0856 & 1.349 \\
\hline $\operatorname{Cg}(5) \cdots \operatorname{Cg}(6)$ & 3.5009 & 26.47 & 3.1338 & 1.561 \\
\hline \multicolumn{5}{|c|}{$\begin{array}{l}{ }^{a} \mathrm{Cg}(1), \mathrm{Cg}(3) \text {, and } \mathrm{Cg}(5) \text { are the centroid positions of the N1-C2-C3-N4-C5, N16-C17-C18- } \\
\mathrm{N} 19-\mathrm{C} 20 \text {, and } \mathrm{N} 25-\mathrm{C} 26-\mathrm{C} 27-\mathrm{N} 28-\mathrm{C} 29 \text { imidazolyl rings, respectively. }{ }^{b} \mathrm{Cg}(2), \mathrm{Cg}(4) \text {, and } \\
\mathrm{Cg}(6) \text { are the centroid positions of the } \mathrm{C} 2-\mathrm{C} 3-\mathrm{C} 6-\mathrm{C} 7-\mathrm{C} 8-\mathrm{C} 9, \mathrm{C} 17-\mathrm{C} 18-\mathrm{C} 21-\mathrm{C} 22-\mathrm{C} 23-\mathrm{C} 24 \text {, } \\
\text { and } \mathrm{C} 26-\mathrm{C} 27-\mathrm{C} 30-\mathrm{C} 31-\mathrm{C} 32-\mathrm{C} 33 \text { phenyl rings, respectively. }{ }^{c} \mathrm{Cg}-\mathrm{Cg}=\text { distance between ring } \\
\text { centroids. }{ }^{d} \text { Beta }=\text { angle between } \mathrm{Cg}(\mathrm{I}) \rightarrow \mathrm{Cg}(\mathrm{J}) \text { vector and normal to plane I. }{ }^{e} \mathrm{CgI} \text { Perp }= \\
\text { perpendicular distance of } \mathrm{Cg}(\mathrm{I}) \text { on ring } \mathrm{J} .{ }^{f} \text { Slippage }=\text { distance between } \mathrm{Cg}(\mathrm{I}) \text { and } \\
\text { perpendicular projection of } \mathrm{Cg}(\mathrm{J}) \text { on ring I. }\end{array}$} \\
\hline
\end{tabular}


Table 5. Oxygen contents of the various residues obtained by subjecting 2 to different treatments.

\section{sample}

monomer 2

2 evacuated under a vacuum of 0.1 mbar

2 evacuated under a vacuum of $5 \times 10^{-2} \mathrm{mbar}$

2 heated to $110^{\circ} \mathrm{C}$ in air

\section{oxygen content $(\%)$}

7.01

4.236

3.245

1.236 $\mathrm{n}_{2} \mathrm{O}^{a}$

1

0.5829

0.4413

0.163

${ }^{a}$ Assuming that the chemical structure of the solid is the same as that of the starting material, $\mathrm{C}_{3} \mathrm{H}_{3} \mathrm{~N}_{2}-\mathrm{CH}_{2} \mathrm{C} \equiv \mathrm{CC} \equiv \mathrm{CCH}_{2}-\mathrm{C}_{3} \mathrm{H}_{3} \mathrm{~N}_{2} \cdot n \mathrm{H}_{2} \mathrm{O}$, and that the amount of oxygen comes solely from water (not from oxidation). 